\title{
Alleviation of Nitrogen and Sulfur Deficiency and Enhancement of Photosynthesis in Arabidopsis thaliana by Overexpression of Uroporphyrinogen III Methyltransferase (UPM1)
}

\author{
Sampurna Garai and Baishnab C. Tripathy* \\ School of Life Sciences, Jawaharlal Nehru University, New Delhi, India
}

OPEN ACCESS

Edited by:

Julian Eaton-Rye,

University of Otago, New Zealand

Reviewed by:

Cecilia Gotor,

Consejo Superior de Investigaciones

Científicas (CSIC), Spain

Ren Maozhi,

Chongqing University, China

*Correspondence:

Baishnab C. Tripathy

bctripathy@mail.jnu.ac.in; baishnabtripathy@yahoo.com

Specialty section: This article was submitted to Plant Cell Biology,

a section of the journal

Frontiers in Plant Science

Received: 25 April 2017 Accepted: 27 December 2017 Published: 23 January 2018

Citation:

Garai S and Tripathy BC (2018)

Alleviation of Nitrogen and Sulfur

Deficiency and Enhancement of Photosynthesis in Arabidopsis thaliana

by Overexpression of

Uroporphyrinogen III Methyltransferase (UPM1).

Front. Plant Sci. 8:2265. doi: 10.3389/fpls.2017.02265
Siroheme, an iron-containing tetrapyrrole, is the prosthetic group of nitrite reductase $(\mathrm{NiR})$ and sulfite reductase (SiR); it is synthesized from uroporphyrinogen III, an intermediate of chlorophyll biosynthesis, and is required for nitrogen $(\mathrm{N})$ and sulfur $(\mathrm{S})$ assimilation. Further, uroporphyrinogen III methyltransferase (UPM1), responsible for two methylation reactions to form dihydrosirohydrochlorin, diverts uroporphyrinogen III from the chlorophyll biosynthesis pathway toward siroheme synthesis. AtUPM1 [At5g40850] was used to produce both sense and antisense plants of Arabidopsis thaliana in order to modulate siroheme biosynthesis. In our experiments, overexpression of AtUPM1 signaled higher NiR (NII) and SiR gene and gene product expression. Increased NII expression was found to regulate and enhance the transcript and protein abundance of nitrate reductase (NR). We suggest that elevated NiR, NR, and SiR expression must have contributed to the increased synthesis of $S$ containing amino acids in AtUPM1 overexpressors, observed in our studies. We note that due to higher $\mathrm{N}$ and $\mathrm{S}$ assimilation in these plants, total protein content had increased in these plants. Consequently, chlorophyll biosynthesis increased in these sense plants. Higher chlorophyll and protein content of plants upregulated photosynthetic electron transport and carbon assimilation in the sense plants. Further, we have observed increased plant biomass in these plants, and this must have been due to increased $\mathrm{N}, \mathrm{S}$, and $\mathrm{C}$ assimilation. On the other hand, in the antisense plants, the transcript abundance, and protein content of NiR, and SiR was shown to decrease, resulting in reduced total protein and chlorophyll content. This led to a decrease in photosynthetic electron transport rate, carbon assimilation and plant biomass in these antisense plants. Under nitrogen or sulfur starvation conditions, the overexpressors had higher protein content and photosynthetic electron transport rate than the wild type (WT). Conversely, the antisense plants had lower protein content and photosynthetic efficiency in $\mathrm{N}$-deficient environment. Our results clearly demonstrate that upregulation of siroheme biosynthesis leads to increased nitrogen and sulfur assimilation, and this imparts tolerance to nitrogen and sulfur deficiency in Arabidopsis thaliana plants.

Keywords: carbon assimilation, electron transport, nitrogen utilization efficiency, nitrogen deficiency photosynthesis, siroheme, sulfur deficiency, uroporphyrinogen III methyltransferase1 (UPM1) 


\section{INTRODUCTION}

The metabolic pathways of carbon, nitrogen and sulfur are intertwined with each other, leading to interdependence. Carbon metabolism includes reactions in both photosynthesis and respiration, whereas nitrogen metabolism, particularly in nonleguminous plants, involves assimilation of nitrate $\left(\mathrm{NO}_{3}^{-}\right)$ from the soil. The supply of soil nitrogen is usually the limiting factor in the yield of plants in most agricultural systems (Robertson and Vitousek, 2009). Development of crops with low $\mathrm{N}$ requirement is expected to be extremely beneficial in addressing the environmental issues and commercial concerns related to the use of chemical fertilizers (Foyer and Ferrario, 1994; Robertson and Vitousek, 2009; Sutton et al., 2011).

After its uptake from the soil, $\mathrm{NO}_{3}^{-}$is reduced to $\mathrm{NH}_{4}^{+}$, using nitrate reductase (NR) and nitrite reductase (NiR). NR is a multi-domain enzyme, which has, as prosthetic groups, molybdenum, Fe-heme and FAD in a 1:1:1 stoichiometry. The NR mediates electron transfer from $\mathrm{NAD}(\mathrm{P}) \mathrm{H}$ to nitrate, reducing it to $\mathrm{NO}_{2}^{-}$(Campbell, 1999). Further, the assimilation of $\mathrm{NO}_{2}^{-}$, thus formed, by $\mathrm{NiR}$ is essentially performed by its prosthetic group siroheme (Murphy et al., 1974) that catalyzes 6 electron reduction of $\mathrm{NO}_{2}^{-}$to $\mathrm{NH}_{4}^{+}$. Siroheme, in turn, is synthesized from uroporphyrinogen III, an intermediate of the biosynthetic pathway of chlorophyll (Chl) (Tanaka and Tanaka, 2007).

Animals are incapable of reducing sulfate and, thus, they require S-containing amino acids or proteins from plant sources. Therefore, sulfate assimilation by plants plays a pivotal role in the sustenance of human life (Tripathy et al., 2010). Plants take up sulfur from the soil, primarily as sulfate. In a plant cell, sulfate is reduced to sulfite by a series of reactions. Sulfite reductase ( $\mathrm{SiR})$, located in the plastids, is responsible for six electron reduction of $\mathrm{SO}_{3}^{2-}$ to $\mathrm{S}^{2-}$ (Murphy et al., 1974) that requires siroheme as the prosthetic group.

In addition to siroheme, both the nitrite reductase and the sulfite reductase have a prosthetic group, which is $[4 \mathrm{Fe}-$ 4S] (Crane and Getzoff, 1996). Siroheme is an iron-containing tetrapyrrole, synthesized in the chloroplast (Murphy and Siegel, 1973); it bridges the iron sulfur cluster and the cysteine residue of the protein, and is involved in the reduction of nitrite and sulfite to ammonia and sulfide (Balk and Schaedler, 2014). Thus, we expect that endogenous levels of the available siroheme and the iron sulfur cluster would play a regulatory role in the metabolic reprogramming of $\mathrm{N}$ and $\mathrm{S}$ assimilation pathways.

Siroheme biosynthesis is dependent on the synthesis of uroporphyrinogen III (Urogen III), a light sensitive compound; it is the first closed tetrapyrrole intermediate of the $\mathrm{Chl}$ biosynthesis pathway (Figure 1). Thus, from the Urogen III branch point of tetrapyrrole biosynthesis, siroheme is synthesized via two methylation steps involving oxidation and ferrochelation (Warren et al., 1990; Leustek et al., 1997; Tripathy et al., 2010). The enzyme uroporphyrinogen III methyltransferase (UPM1) catalyzes methylation at the $\mathrm{C} 2$ and $\mathrm{C} 7$ positions of Uroporphrinogen III to form dihydrosirohydrochlorin
(Warren et al., 1990; Leustek et al., 1997): this reaction is a rate limiting step. The dihydrosirohydrochlorin undergoes oxidation to form sirohydrochlorin. The latter is converted to siroheme by sirohydrochlorin ferrochelatase (SIRB) that catalyzes the chelation of iron into the macrocycle (RauxDeery et al., 2005). We note that the siroheme biosynthesis pathway is conserved in bacteria, yeast and higher plants. In bacteria, sirohydrochlorin cobalt chelatase inserts cobalt into sirohydrochlorin leading to vitamin $\mathrm{B}_{12}$ biosynthesis (Brindley et al., 2003). Heme is crucial for many biological processes and there are reports for the existence of pathways for the conversion of siroheme to heme in some denitrifying and sulfur reducing bacteria (Bali et al., 2011, 2014). Thus, the enzyme UPM1 is crucial for many essential biological processes.

All the three enzymes, NiR, NR, and SiR, are regulated by light via a phytochrome-mediated signaling cascade (Faure et al., 1991). The promoters of SiR, NII, and NIA2 have light responsive elements (LRE). Interestingly, both siroheme biosynthetic genes i.e., UPM1 and SIRB are also upregulated by light and have LRE in their promoters for interaction with the phytochromes (Garai et al., 2016). This demonstrates the pivotal role of light in the regulation of most of the $\mathrm{N}$ and $\mathrm{S}$ assimilation pathway.

In Arabidopsis thaliana, uroporphyrinogen III methyl transferase is coded by UPM1 [At5g40850]. Further, AtUPM1 is a nuclear-encoded plastidic enzyme containing a transit peptide of 28 amino acids (Leustek et al., 1997). It is well known that the assimilation of $\mathrm{N}$ and $\mathrm{S}$ in plants is regulated by siroheme (Tripathy et al., 2010), and that the knockout lines for AtUPM1 in A. thaliana are lethal (Tripathy et al., 2010; Saha et al., 2012). In the present study, we have analyzed the impact of over-expression or reduced expression of AtUPM1 on N, S and C assimilation. We demonstrate here, in A. thaliana, that overexpression of AtUPM1 enhances $\mathrm{N}$ and $\mathrm{S}$ assimilation, protein content and photosynthesis rates. Further, we demonstrate that overexpression of AtUPM1 protects plants from nitrogen and sulfur deficiency.

\section{MATERIALS AND METHODS}

\section{Plant Material and Growth Conditions}

A. thaliana seeds were soaked in water and kept for $48 \mathrm{~h}$ at $4^{\circ} \mathrm{C}$ (i.e., they were stratified). Seedlings were germinated and grown, at $21^{\circ} \mathrm{C}$, in agropeat:vermiculite mixture (4:1) in pots (10-20 per pot under cool-white-fluorescent light $(80 \mu \mathrm{mol}$ photons $\mathrm{m}^{-2} \mathrm{~s}^{-1}$ ), and a $14 \mathrm{~h}$ light $/ 10 \mathrm{~h}$ dark photoperiod.We also grew plants under sterile conditions for some experiments. For this, the seeds were sterilized and plated on half strength Murashige \& Skoog (MS) media for $10 \mathrm{~d}$ (Murashige and Skoog, 1962). These seedlings were then transferred to halfstrength MS plates, one plant per plate. In addition, we grew plants under nutrient deficient conditions. For this, A. thaliana seeds were grown in half-strength MS plates for 10 days and subsequently transferred to $\mathrm{N}$-deficient or S-deficient growth media, and grown for additional 15 days. Here again, each plate contained one plant. We also grew wild type (WT) 


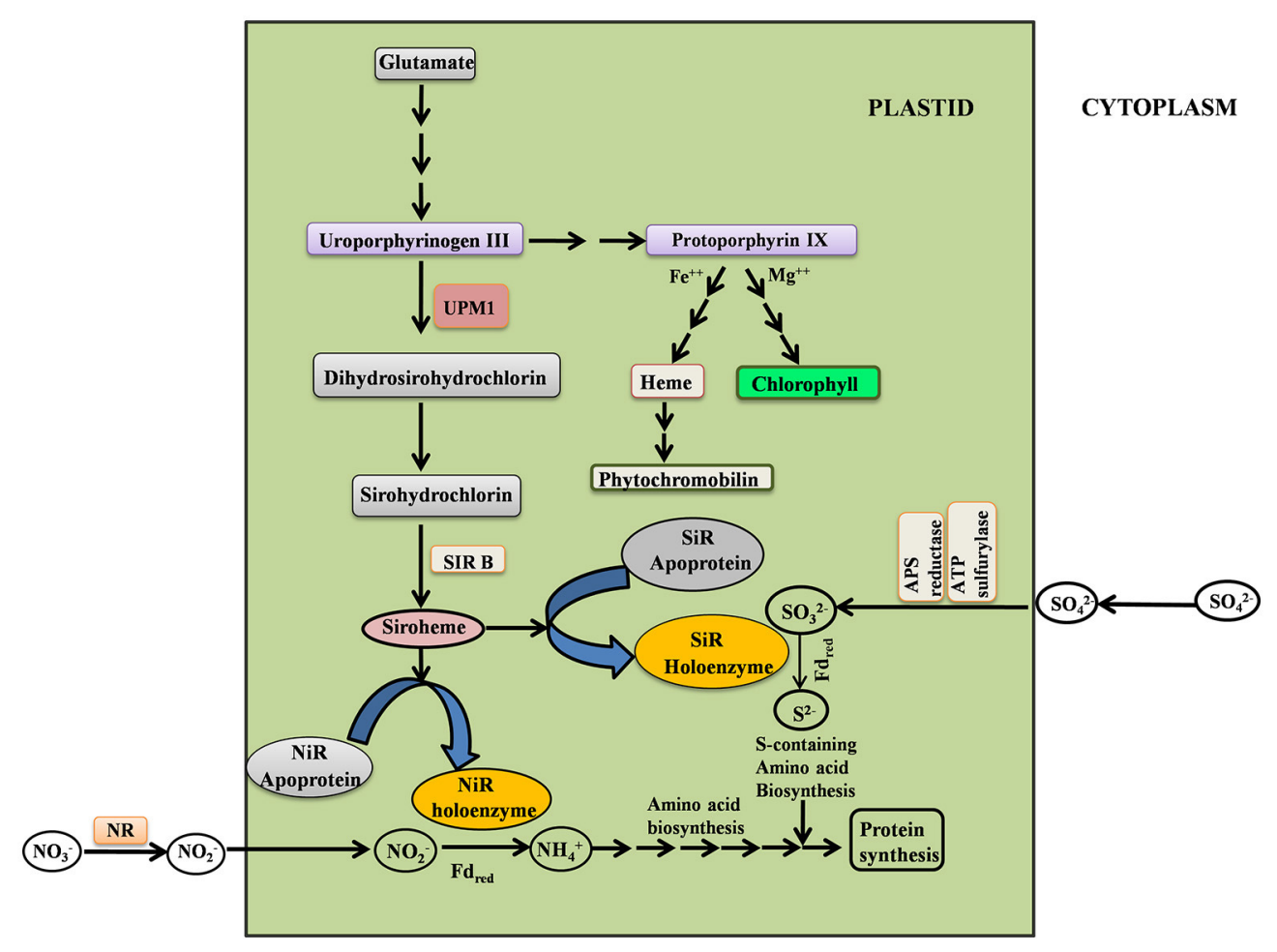

FIGURE 1 | Simplified scheme depicting the interrelationship between siroheme, chlorophyll, heme biosynthesis and N \& S assimilation. UPM1, Uroporphyrinogen III methyl transferase; SIRB, Sirohydrochlorin Ferrochelatase; NR, Nitrate reductase; NiR, Nitrite reductase; SiR, Sulfite reductase.

and transgenic plants directly on nutrient deficient media (see below for details) in order to have plants to induce severe $\mathrm{N}$ or $\mathrm{S}$ deficiency. For a proper comparison, both $\mathrm{WT}$ and transgenic plants were grown on a single square plate.

Growth media were prepared, as described below. We used Hoagland medium (Hoagland and Arnon, 1950), which had the following composition: (solution I) $\mathrm{KH}_{2} \mathrm{PO}_{4}$ (1 M); (solution II) $\mathrm{MgSO}_{4} \cdot 7 \mathrm{H}_{2} \mathrm{O}(1 \mathrm{M})$; (solution III): $\mathrm{Ca}\left(\mathrm{NO}_{3}\right)_{2} \cdot 4 \mathrm{H}_{2} \mathrm{O}(1 \mathrm{M})$; (solution IV): Ferric citrate (0.5\%); (solution V): $\mathrm{H}_{3} \mathrm{BO}_{3}(0.05 \%)$, $\mathrm{MnSO}_{4} .7 \mathrm{H}_{2} \mathrm{O}(0.05 \%), \mathrm{ZnSO}_{4} .7 \mathrm{H}_{2} \mathrm{O}(0.005 \%), \mathrm{CuSO}_{4} .7 \mathrm{H}_{2} \mathrm{O}$ (0.002\%), and $\mathrm{Na}_{2} \mathrm{MoO}_{4} \cdot 2 \mathrm{H}_{2} \mathrm{O}(0.001 \%)$. One liter of the growth medium contained $1 \%$ sucrose and $1,2,5,1$, and $1 \mathrm{ml}$ each of solutions I, II, III, IV, and V, respectively. The $\mathrm{pH}$ of the media was 5.7 with $0.6 \%$ agar as a solidifying agent. For the nitrogendeficient media, we simply replaced $\mathrm{Ca}\left(\mathrm{NO}_{3}\right)_{2}$ with $\mathrm{CaCl}_{2}$, and for the sulfur deficient media, we replaced $\mathrm{MgSO}_{4}$ with $\mathrm{MgCl}_{2}$.

\section{qRT-PCR}

The total RNA was isolated from the plant samples using Tri reagent (Sigma) from 3 different plants (i.e., three biological replicates). The first strand cDNA was synthesized using cDNA synthesis kit (Verso, USA). Relative expression of different genes was studied by performing qRT-PCR on an ABI Prism 7500 Sequence Detection System using the default program (Applied Biosystems, USA). Three technical replicates were taken per sample. We used $10 \mu \mathrm{l}$ reaction mixtures, which contained $0.5 \mu \mathrm{l}$ cDNA, 5 pmol primers (see Table 4) and $5 \mu \mathrm{l}$ 2xSYBR Green PCR Master Mix (Applied Biosystems, USA). The reference gene used was Actin 2. The relative gene expression data were analyzed using $2^{-\Delta \Delta \mathrm{Ct}}$ quantitation methods (Livak and Schmittgen, 2001).

\section{Cloning of AtUPM1 cDNA in Binary Vector and Transformation of Arabidopsis thaliana}

The AtUPM1 coding DNA sequence (CDS) (accession \# NM_123450) of the complete AtUPM1 gene (At5g40850), consisting of $1,110 \mathrm{bp}$, was amplified from the cDNA library of WT A. thaliana ( $\mathrm{Col} 0$ ), using the gene specific primer pair: F-5'ATGGCTCTTGTTCAGCGGATTC3' and R 5'CTACCGGGTCTCTACAA GGCA 3'; it was then cloned into pGEMT-Easy vector (Promega corporation, USA). The pGEMT-Easy recombinant plasmid, containing the full length AtUPM1 cDNA, was digested with EcoRI and then cloned into the modified PCAMBIA 1304 binary vector at the EcoRI site in both the sense and the antisense orientation, under the control of CaMV35S promoter (Supplementary Figure 1). The pCAMBIA 1304 binary vector was modified as described earlier (Pattanayak et al., 2005) and hygromycin-resistance $(h p t)$ marker gene was replaced with kanamycin-resistance (nptII) gene. The pCAMBIA1304::AtUPM1 construct was introduced into Agrobacterium tumefaciens strain GV3101 for the transformation of $A$. thaliana (Col-0) by the floral dip method 
and vacuum infiltration (Clough and Bent, 1998). The seeds of the transformed plants (the T1 generation) were screened on half-strength MS agar medium containing $50 \mathrm{mg} \mathrm{l}^{-1}$ kanamycin and were then grown up to the $\mathrm{T} 4$ generation. We used these T4 homozygous lines for all the studies reported in this paper.

\section{PCR}

PCR was carried out with the genomic DNA of WT and transgenic plants serving as the template. The primers used were: 35S Int F: $5^{\prime}$ CCC ACT ATC CTT CGC AAG AC $3^{\prime}$ and AtUPM1 R: 5' CTACCGGGTCTCTACAAGGCA $3^{\prime}$ for the PCR confirmation of the sense plants; the positive plants yielded an amplicon of $1.3 \mathrm{~kb}$ (Supplementary Figure 2A). For the PCR confirmation of antisense plants, the primers used were: 35S Int F: 5' CCC ACT ATC CTT CGC AAG AC and AtUPM1 F: ATGGCTCTTGTTCAGCGGATTC; these yielded an amplicon of $1.3 \mathrm{~kb}$ for the positive antisense plants (Supplementary Figure 2B).

\section{Southern Blot Analysis of the Transgenic Plants}

The presence of AtUPM1 transgene was analyzed by Southern blot analysis. Thirty micrograms $(\mu \mathrm{g})$ of genomic DNA from leaves of the T3 generation WT and transgenic plants (control and transgenic lines 4, 6, 7, and 9) were digested overnight, with XbaI enzyme. The digested DNA was resolved on $0.7 \%$ agarose gel and blotted onto Nylon 66 (MDI, USA) membrane. PCR was carried out using AtUPM1 F for the preparation of the probe, and was labeled with $\left[\alpha^{32} \mathrm{P}\right] \mathrm{dCTP}$, using a radioactive random primer labeling kit (Amersham-GE, UK). The Southern blot was developed according to Sambrook and Russell (2001). All further analyses were carried out on homozygous lines of T4 through T7 generations.

\section{Protein and Pigment Estimation}

The soluble protein, from the leaves, was estimated as described previously (Bradford, 1976). Ten biological replicates were taken for the analysis reported here. Total chlorophyll was extracted, from leaves, in $90 \%$ ammoniacal acetone, and estimated as described previously (Porra et al., 1989), whereas, the carotenoid content was also determined, as described previously (Wellburn and Lichtenthaler, 1984).

\section{Western Blot Analysis}

Crude protein extracts were prepared from 3-week-old leaves for immunoblot analysis (Jilani et al., 1996). Total protein was resolved on a $12.5 \%$ SDS-PAGE (Laemmli, 1970), which was then transferred onto nitrocellulose membranes for western blot analysis. Polyclonal antibodies raised against Arabidopsis thaliana proteins were used for protein blot analyses of UPM1 (1:2,000), NiR (1:2,500), and NR (1:1,000). The bands in the immunoblots were evaluated using AlphaEase FC software.

\section{Nitrate Reductase and Nitrite Reductase Assays}

Nitrate and nitrite reductase activities were measured, as described previously (Kaiser and Lewis, 1984; Takahashi et al., 2001).

\section{Pulse Amplitude Modulation (PAM) Measurements of $\mathrm{Chl}$ a Fluorescence}

Chl $a$ fluorescence measurement is used as a non-destructive and non-invasive signature of photosynthesis (Govindjee et al., 1986; Baker, 2008). The fluorescence from the ventral side of the leaf was measured with PAM-2100 chlorophyll fluorometer (Walz, Germany) at room temperature (Dutta et al., 2009). Leaves were dark-adapted for $20 \mathrm{~min}$ before fluorescence measurements (Demmig et al., 1987). The initial minimal fluorescence (Fo) was recorded by turning on a weak measuring beam set to a frequency of $0.6 \mathrm{kHz}$. The maximum fluorescence $(\mathrm{Fm})$ was measured after a red $\left(\lambda_{650}\right.$ $\mathrm{nm})$ saturation flash $\left(3,000 \mu \mathrm{mol}\right.$ photons $\left.\mathrm{m}^{-2} \mathrm{~s}^{-1}\right)$ was given. The quantum efficiency of PSII in dark-adapted leaves was estimated as $\mathrm{Fv} / \mathrm{Fm}(\mathrm{Fv}=\mathrm{Fm}-\mathrm{Fo})$ (Schreiber and Armond, 1978).

Electron transport rate (ETR) was estimated from the following relation: Yield $\times$ PAR $\times 0.5 \times 0.84$, where Yield is the overall photochemical quantum yield (inferred from $\left(F_{m}{ }_{m}\right.$ $\left.F_{t}\right) / F_{m}^{\prime}=\Delta \mathrm{F} / F_{m}{ }_{m}$, with $F_{t}$ being the measured fluorescence yield at any given time (t) and $F_{m}^{\prime}$ the maximal fluorescence yield in a pulse of saturating light when the sample is pre-illuminated); PAR is photon flux density of incident photochemically active radiation ( $\mu \mathrm{mol}$ photons $\mathrm{m}^{-2} \mathrm{~s}^{-1}$ ); the 0.5 factor is used because the absorbed light energy is almost equally distributed between the two photosystems, whereas, 0.84 denotes that $84 \%$ of the incident quanta are absorbed by the leaf. The non-photochemical quenching (NPQ) of the excited state of Chl $a$ was calculated as $\left(\mathrm{F}_{\mathrm{m}}-\mathrm{F}_{\mathrm{m}}\right) / \mathrm{F}_{\mathrm{m}}^{\prime}$ (Schreiber, 2004).

\section{Photosynthesis Light-Response Curve}

Light-response curve for photosynthesis of WT and AtUPM1x plants, grown for 5 weeks, in an agropeat:vermiculite (3:1) mixture, under $80 \mu \mathrm{mol}$ photons $\mathrm{m}^{-2} \mathrm{~s}^{-1}$ light, was measured using an infrared gas analyzer GFS-3000 (Walz, Germany). Sample-chamber $\mathrm{CO}_{2}$ concentration was maintained at 400 $\mu l L^{-1}$. The relative humidity was set at $70 \%$. Air temperature, in the sample chamber, was maintained at $25^{\circ} \mathrm{C}$. Leaves were preexposed for $20 \mathrm{~min}$ at $200 \mu \mathrm{mol}$ photons $\mathrm{m}^{-2} \mathrm{~s}^{-1}$ before $\mathrm{CO}_{2}$ assimilation was monitored. $\mathrm{Net} \mathrm{CO}_{2}$ assimilation was measured at several different light intensities.

\section{Porphobilinogen Synthase (PBGS) Assay}

Leaves were collected from 25-day-old WT, AtUPM1x and antiUPM1 $A$. thaliana plants grown at $21^{\circ} \mathrm{C}$, under cool-whitefluorescent light $\left(80 \mu \mathrm{mol}\right.$ photons $\left.\mathrm{m}^{-2} \mathrm{~s}^{-1}\right)$ in a $14 \mathrm{~h}$ light $/ 10 \mathrm{~h}$ dark photoperiod. The leaves $(250 \mathrm{mg}$ ) were hand homogenized in $5 \mathrm{~mL}$ of $0.1 \mathrm{M}$ Tris $(\mathrm{pH} 7.6)$ and $0.01 \mathrm{M} \beta$-mercaptoethanol solution at $4^{\circ} \mathrm{C}$. The homogenate was centrifuged at $12,000 *$ $\mathrm{g}$ for $10 \mathrm{~min}$ at $4^{\circ} \mathrm{C}$. The supernatant was used for enzymatic assays. The PBGS enzyme activity was determined by measuring 
the amount of PBG formed from ALA, as described earlier (Sood et al., 2005). PBG formed was calculated using the absorption coefficient of $6.2 * 10^{4} \mathrm{M}^{-1} \mathrm{~cm}^{-1}$, at $555 \mathrm{~nm}$ (Hukmani and Tripathy, 1994).

\section{Porphobilinogen Deaminase (PBGD) Assay}

Leaves $(250 \mathrm{mg})$ collected from the WT, AtUPM1x and antiUPM1 A. thaliana plants, grown under cool-whitefluorescent light $\left(80 \mu \mathrm{mol}\right.$ photons $\left.\mathrm{m}^{-2} \mathrm{~s}^{-1}\right)$ under a $14 \mathrm{~h}$ light $/ 10 \mathrm{~h}$ dark photoperiod at $21^{\circ} \mathrm{C}$, were hand homogenized in $5 \mathrm{ml}$ of $0.1 \mathrm{M}$ Tris ( $\mathrm{pH} 7.6$ ) and $0.01 \mathrm{M} \beta$-mercaptoethanol solution at $4^{\circ} \mathrm{C}$. The homogenate was centrifuged at $10,000 \mathrm{rpm}$ for $10 \mathrm{~min}$ at $4^{\circ} \mathrm{C}$. The enzyme activity was assayed, using the supernatant; the amount of porphyrin synthesized in $1.0 \mathrm{ml}$ of the reaction mixture was calculated, using the extinction coefficient of $5.48 \times 10^{5} \mathrm{M}^{-1} \mathrm{~cm}^{-1}$ at $405 \mathrm{~nm}$ (Bogorad, 1962).

\section{Amino Acid Estimation}

Cysteine content was estimated as described earlier (Gaitonde, 1967). Fresh leaves were homogenized in 5\% (w/v) ice-cold perchloric acid, and then centrifuged, for $1 \mathrm{~h}$, at 3,000 g at $4^{\circ} \mathrm{C}$. The supernatant was filtered through Whatman No. 1 filter paper. The filtrate was treated with acid ninhydrin reagent. The absorbance was read at $580 \mathrm{~nm}$ and the amount of cysteine was calculated with reference to the calibration curve obtained under similar conditions for standard cysteine.

The methionine content was estimated as described earlier (Horn et al., 1946). Fresh leaf samples (about $0.5 \mathrm{~g}$ ) were refluxed with $6.0 \mathrm{~mL} 2.0 \mathrm{~N} \mathrm{HCl}$ for $1 \mathrm{~h}$, followed by evaporation on water bath with the addition of $1.0 \mathrm{~g}$ of activated charcoal. The filtrate was collected and the $\mathrm{pH}$ was adjusted to be 6.5 with the addition of $10 \mathrm{~N} \mathrm{NaOH}$. The volume was made upto $50 \mathrm{ml}$ with the addition of distilled water. To $25 \mathrm{ml}$ of this solution, $3 \mathrm{ml}$ of $10 \% \mathrm{NaOH}, 0.15 \mathrm{ml}$ of $10 \%$ sodium nitroprusside, $1 \mathrm{ml}$ of glycine solution (3\%) and $2 \mathrm{ml}$ of phosphoric acid were added in the order mentioned. This suspension was vigorously shaken and absorbance changes were measured at $520 \mathrm{~nm}$ to calculate the methionine concentration in the sample.

\section{Transmission Electron Microscopy}

Leaves of $A$. thaliana transgenic plants were vacuum infiltrated with $2.5 \%$ glutaraldehyde solution for $30 \mathrm{~min}$ and kept overnight in the same solution (Karnovsky, 1965). The above solution was replaced by $0.1 \mathrm{M}$ sodium-phosphate buffer ( $\mathrm{pH} 7.0$ ), and then we followed the method described by Jiang et al. (2011). Leaf sections were viewed under a Transmission Electron Microscope (JEOL 2100F).

\section{Statistical Analyses}

Microsoft Excel was used for the statistical analysis. The number of biological replicates taken for each experiment is noted in the figure legends. After the calculation of averages, standard deviations or standard errors for each of the parameters were determined and an unpaired Student's $t$-test was used to assess the difference between the WT and the transgenic plants, grown under different conditions.

\section{RESULTS}

\section{Transformation of AtUPM1cDNA in Arabidopsis thaliana and Transgenic Screening}

The CDS region (accession no. NM_123450), consisting of 1110 base pair, was amplified from the cDNA library of WT A. thaliana (Col 0), as described in details under the Material and Methods. Confirmation of the transgenics, as well as of the copy number of the integrated gene, was checked by Southern blot analysis. Besides the endogenous gene of the WT, S4 and S6 transgenic lines had double insertion of the transgene, whereas, the S7 and S9 lines had single copy integration. The lines labeled as antisense "a" (ASa)and antisense "d" (Asd) had single copy integration, while that labeled as antisense " $\mathrm{f}$ " had a copy number of four (Supplementary Figure 2C).

The selected homozygous transgenic (T4) lines were analyzed in the leaves, by quantitative RT-PCR, for the abundance of AtUPM1 message. The highest gene expression was found in the S7 line, which had a 3.5-fold higher transcript abundance than the WT. The other transgenic lines, i.e., S9, S6, and S4, respectively, had 2.4, 2.2, and 1.3 fold higher expression of UPM1. However, in the antisense lines, there was a decrease in the expression of AtUPM1 message by $12-47 \%$ (Supplementary Figure 2D).

The overexpression and underexpression of the gene product in the transgenics was monitored by immunoblot analysis. Similar to transcript abundance, the AtUPM1 protein expression was higher $(62-72 \%)$ in S7 and S9 lines than in the WT. On the contrary, antisense lines ASa, ASd, and ASf had lower (9-66\%) AtUPM1 protein abundance (Supplementary Figures 2E,F).

\section{The AtUPM1 Overexpressors Modulated Nitrogen Assimilatory Enzymes Nitrite Reductase: Gene Expression, Protein Abundance, and Enzyme Activity}

UPM1 is the first enzyme involved in the biosynthesis of siroheme, the prosthetic group of nitrite reductase (see section Introduction). Thus, we suggest that the overexpression of AtUPM1 may lead to modulation of nitrite reductase. Figure 2A shows that the overexpression of AtUPM1results in increased $\mathrm{NiR}$ gene expression. As revealed by q-RT PCR, the S4, S6, S7, and S9 overexpressor lines had 2.5-, 1.93-, 2.91-, and 3.65-fold higher gene expression than the WT (Figure 2A). Further, the western blot analysis, of the same lines, shows an increased abundance of nitrite reductase by $125,106,87$, and $174 \%$, respectively (Figures $\mathbf{2 B}, \mathbf{C}$ ). On the other hand, the antiUPM1 plants had reduced gene and protein expression of NiR. However, ASd and ASf lines had 29 to $12 \%$ lower gene expression than the WT (Figure 2A); this was accompanied by a decrease (38 and 10\%) in the abundance of nitrite reductase (Figures 2B,C). The ASa line was a very weak transgenic line and did not have any significant impact on gene expression or protein abundance of NiR. To understand the efficacy of the increased gene and protein expression of UPM1 involved in 

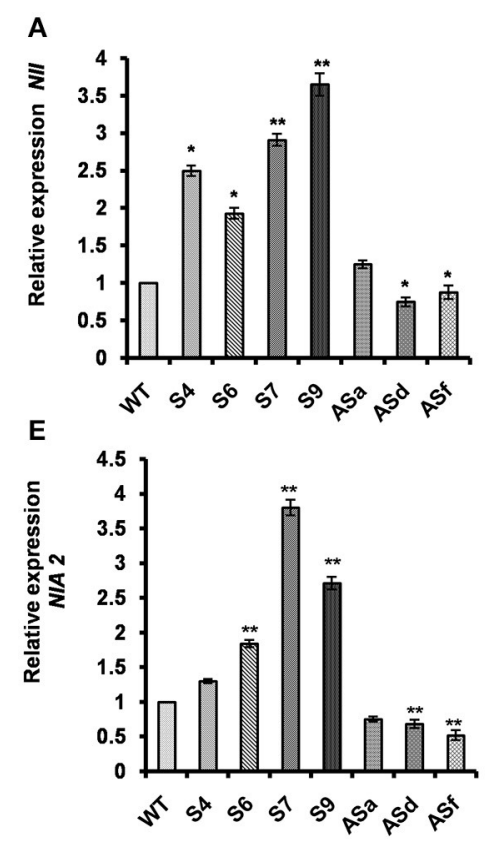

B
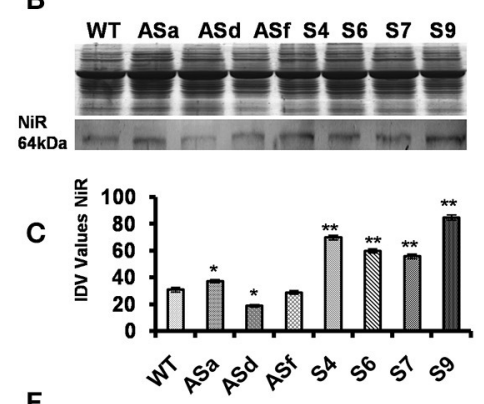

$\mathbf{F}$

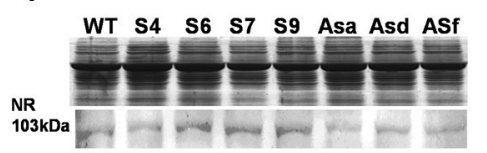

G

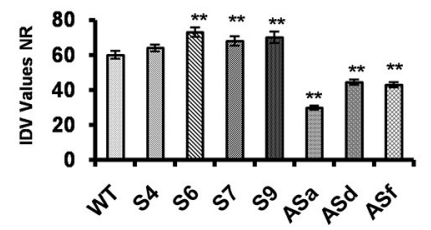

D
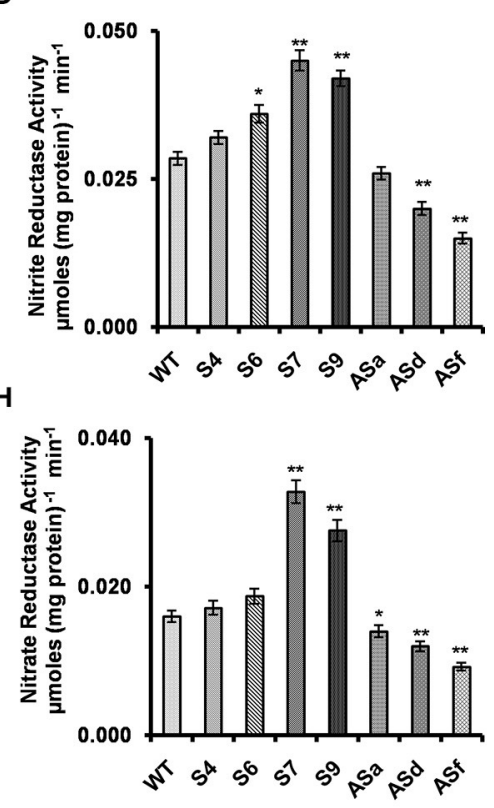

FIGURE 2 | Modulation of nitrite reductase and nitrate reductase in the transgenics. The WT and AtUPM1 overexpressor and antisense plants were grown photoperiodically ( $14 \mathrm{~h} \mathrm{~L}$ and $10 \mathrm{~h} \mathrm{D}$ ) in MS plates for 25 days under cool-white fluorescent light at $21^{\circ} \mathrm{C}$. (A) The changes in gene expression of nitrite reductase (NII) in transgenics monitored by qRT PCR. (B) SDS PAGE (12.5\%) of protein (20 $\mu \mathrm{g})$ isolated from the WT and transgenic plants to check equal loading and the immunoblot of the plant protein to check the abundance of nitrite reductase (NiR). (C) The quantification of the NiR blot by densitometric analysis using Alpha Ease FC software. (D) The NiR enzyme activity of the WT and AtUPM1 transgenic plants. (E) The changes in gene expression of nitrate reductase (NIA2) in transgenics monitored by qRT PCR. (F) SDS-PAGE (12.5\%) of protein $(20 \mu \mathrm{g})$ isolated from the WT and transgenic plants to check equal loading and the immunoblot of the plant protein to check the abundance of nitrate reductase (NR). (G) Quantification of the NR blot by densitometric analysis using Alpha Ease FC software. (H) NR enzyme activity of the WT and AtUPM1 transgenic plants. Western blot data is an average of three independent replicates. qRT-PCR data are expressed as the mean \pm SEM of three independent experiments performed in triplicate. For enzyme assay, the experiment was repeated three times and each datapoint is an average of 5 biological replicates $(n=5)$. Error bars, S.D. Asterisks indicate significant difference determined by Student's $t$-test compared to control $\left({ }^{\star} P<0.05\right.$, $\left.{ }^{\star \star} P<0.01\right)$ IDV values represent integrated density values as calculated by the Alpha Ease FC software.

the biosynthesis of the cofactor siroheme, the nitrite reductase activity was monitored in WT and transgenic plants. The NiR activity in the transgenic lines S4, S6, S7, and S9 was higher by $14,29,60$, and $50 \%$ than that of WT. On the other hand, the antisense plants had lower (8-46\%) NiR activity than the WT (Figure 2D).

\section{Nitrate Reductase: Gene Expression, Protein Abundance, and Enzyme Activity}

The substrate for chloroplastic $\mathrm{NiR}, \mathrm{NO}_{2}^{-}$, is generated by the cytoplasmic enzyme NR that utilizes $\mathrm{NO}_{3}^{-}$as its substrate. Therefore, the gene expression, the protein abundance and the enzymatic activity of NR were monitored in the WT and all the transgenic plants. As compared to WT, the transcript abundance of NIA2 in AtUPM1overexpressors was higher by 30,84, 280, and $170 \%$ in transgenic S4, S6, S7, and S9, respectively (Figure 2E). Similarly, the nitrate reductase protein abundance in S4, S6, S7, and S9 were higher than WT by $10,20,50$, and $45 \%$ respectively (Figures 2F,G). In antiUPM1 plants both gene expression and protein abundance of NR was substantially lower than WT. The enzyme activity of nitrate reductase increased in sense transgenic lines. The NR activity in S4, S6, S7, and S9 was 8, 19, 106, and 75\% higher than in WT. On the contrary, in anti UPM1 transgenic lines the NR activity was substantially lower (13-43\%) than the WT (Figure 2H).

\section{Overexpression of UPM1 Increased Protein and Pigment Content}

\section{Protein Content}

The total protein content of all the overexpressors (the sense plants) was higher than in the WT (Figure 3A): proteins in the shoots of AtUPM1x S4, S6, S7, and S9 were 15-30\% higher. However, in the antisense plants, the protein content was lower $(15-23 \%)$. The reason for this result is most likely due to changes in gene expression as well as protein abundance and the activity of nitrogen assimilation enzymes ( $\mathrm{NiR}$ and $\mathrm{NR}$ ): higher in the sense plants and lower in the antisense plants. We note that the lowering of these enzymes, in the antisense plants, may have been due to siroheme limitation.

\section{Chlorophyll Content}

Increase in the total protein content in AtUPM1x plants (S4, S6, S7, and S9) was accompanied by higher chlorophyll content: 20$35 \%$ more than in the WT (Figure 3B). In contrast, the antisense plants (antiUPM1) had reduced (13-25\%) and Chl content than in the WT. 

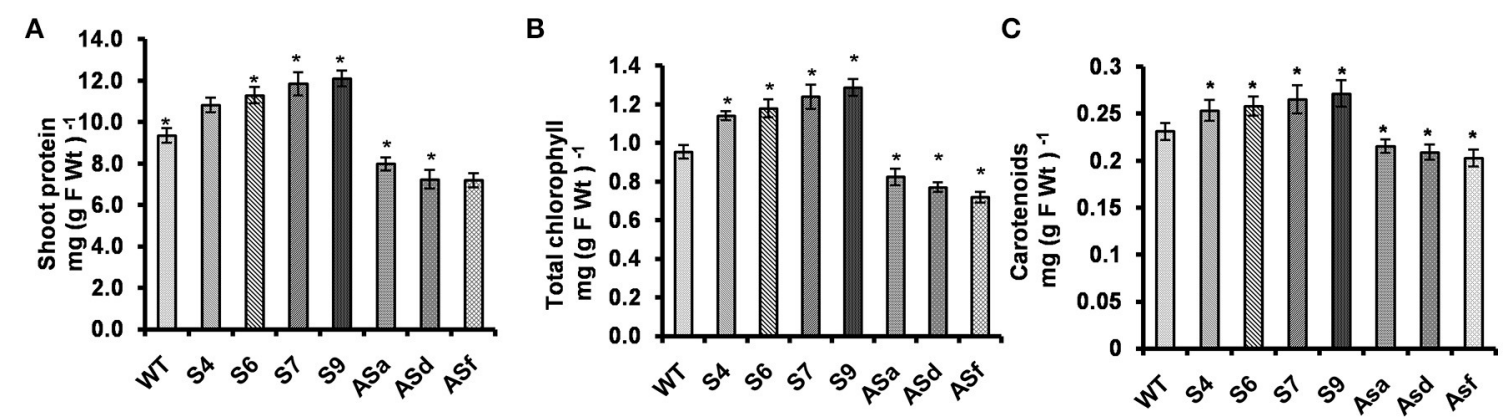

FIGURE 3 | AtUPM1 modulates the protein content, chlorophyll and the carotenoid content. The WT and AtUPM1 overexpressor and antisense plants were grown photoperiodically (14 h L and 10 h D) in MS plates for 25 days under cool-white fluorescent light at $21^{\circ} \mathrm{C}$. (A) Shoot protein content. (B) Shoot chlorophyll content. (C) Shoot carotenoid content. The experiments were repeated three times and each datapoint is an average of ten biological replicates for (f), (g) and (h). Error bars, S.D. Asterisks indicate significant difference determined by Student's t test compared to control $\left({ }^{\star} P<0.05\right.$, $\left.{ }^{\star \star} P<0.01\right)$ IDV values represent integrated density values as calculated by the Alpha Ease FC software.

\section{Carotenoid Content}

We note that the AtUPM1x lines S4, S6, S7, and S9 had higher (10-15\%) carotenoid content than the WT (Figure 3C). However, the antisense plants had reduced (7-12.5\%) carotenoid content.

\section{AtUPM1 Modulates the Expression of Genes Involved in Chlorophyll Biosynthesis}

Differences in Chl content of the transgenic plants, used in this study, led us to ask if AtUPM1 expression can modulate the gene expression of the enzymes involved in Chl biosynthesis. For this purpose, we chose S7, an overexpressor having higher $\mathrm{Chl}$ content, and ASd, an underexpressor having lower Chl content. (We did not use ASf because it had multiple insertion of the transgene.) Using quantitative reverse transcription (qRT)-PCR, we analyzed the transcript abundance of enzymes involved in the biosynthesis of protoporphyrin IX and of Mg-tetrapyrrole. The gene expression of porphobilinogen synthase (PBGS), responsible for the synthesis of the pyrrole ring porphobilinogen (PBG), increased by $22 \%$ in S7, a sense plant; however, it decreased by $24 \%$ in ASd (Figure 4A). Further, the gene expression of PBG deaminase (PBGD) and uroporphyrinogen III synthase (UROS), involved in cyclization of four molecules of PBG to uroporphyrinogen III, was upregulated by 60 and $128 \%$ in the S7 line, and was downregulated by 24 and $20 \%$ in the underexpressor respectively (Figures 4B,C). In contrast, the gene expression of uroporphyrinogen III decarboxylase (UROD) (AT2G40490.1), responsible for decarboxylation of uroporphyrinogen III to coporporphyrinogen III, declined by $\sim 50 \%$ in S7. However, in ASd, the transcript abundance of UROD was almost similar to that of the WT plant (Figure 4D).

In S7, a sense plant, the message abundance of coproporphyrinogen III oxidase $(C P O X)$, which converts coproporphyrinogen III to protoporphyrinogen IX, was higher (35\%) than in the WT, and lower (33\%) in ASd, an antisense plant (Figure 4E). In the same vein, the gene expression of protoporphyrinogen IX oxidase $(P P O X)$, responsible for the removal of six electrons from the macrocycle of protoporphyrinogen IX to form protoporphyrin IX, was higher (by 130\%) in S7 than in the WT, and lower (by 22\%) in Asd (Figure 4F).

To ascertain the impact of UPM1 overexpression on the $\mathrm{Mg}$-branch of tetrapyrrole biosynthesis, the gene expression of two selected enzymes involved in the conversion of porphyrin IX to chlorophyll was monitored: (1) Mg-chelatase, which is responsible for chelation of $\mathrm{Mg}$ to protoporphyrin IX moiety, which directs porphyrin to the Mg-branch of tetrapyrrole biosynthesis; we used only the CHLH moiety of this enzyme. (2) Mg-protoporphyrin IX: S-adenosyl methionine methyl transferase $(M g M T)$, which converts Mg-Proto IX to $\mathrm{Mg}$ protoporphyrin IX monomethyl ester (MPE). Using qRT, we showed that the message abundance of $\mathrm{CHLH}$ increased by $97 \%$ in S7, a sense plant and decreased by $20 \%$ in ASd, an antisense plant (Figure 4G). The gene expression of $M g M T$ was higher by $76 \%$ in S7, and lower by $14 \%$ in ASd than the WT plant (Figure 4H). Further, for the Chl biosynthesis pathway, we observed that the gene expression of protochlorophyllide oxidoreductase $\mathrm{C}(P O R C)$, a light-inducible gene responsible for photo-transformation of protochlorophyllide to chlorophyllide, increased by $79 \%$ in the overexpressor S7, and decreased by $31 \%$ in the underexpressor ASd (Figure 4I).

\section{The Activities of Chlorophyll Biosynthetic Enzymes}

To ascertain if increased or decreased expression of the genes involved in Chl biosynthesis in the sense and antisense plants corresponds to changes in enzymatic activities, catalytic reactions of the following two important successive enzymes of Chl biosynthetic pathway were monitored in the transgenics.

Porphobilinogen Synthase: PBGS mediates the condensation of two molecules of ALA to yield the pyrrole moiety porphobilinogen (PBG) (Tanaka and Tanaka, 2007). In comparison with the WT, the PBGS activity increased by $23 \%$ in the S7 overexpressor, the sense plant, 

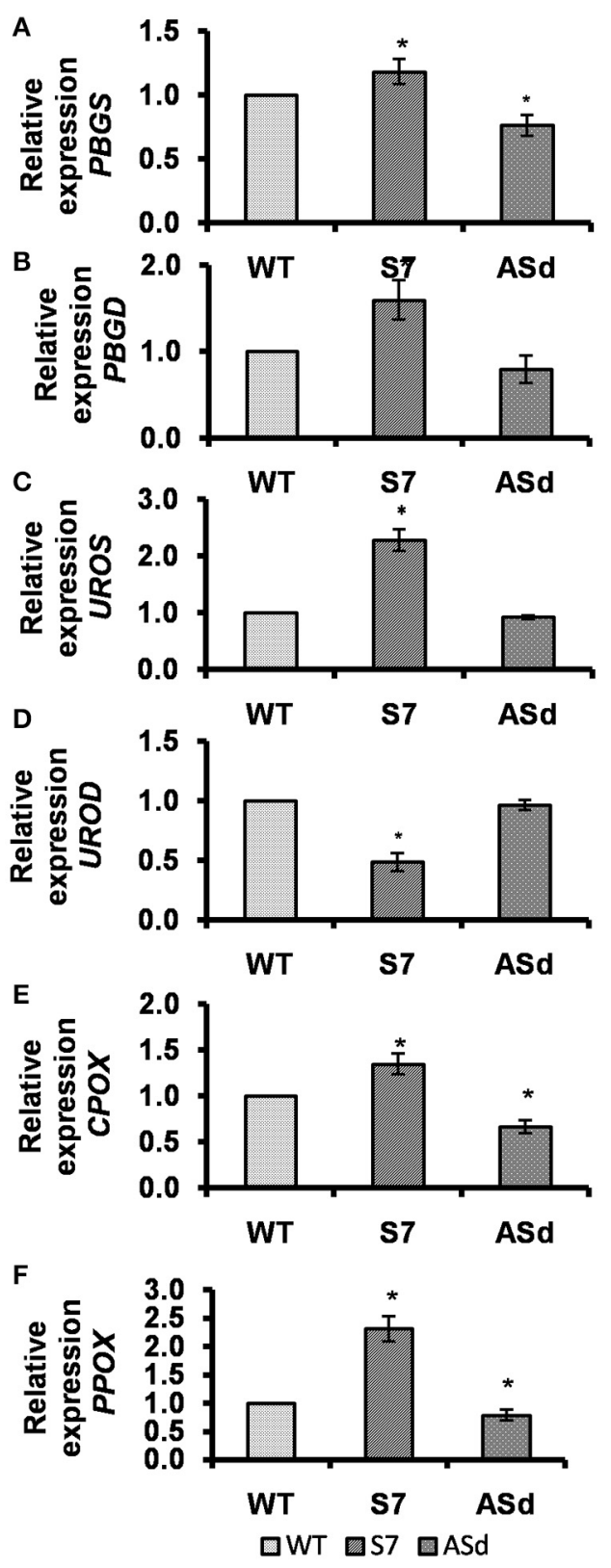

G

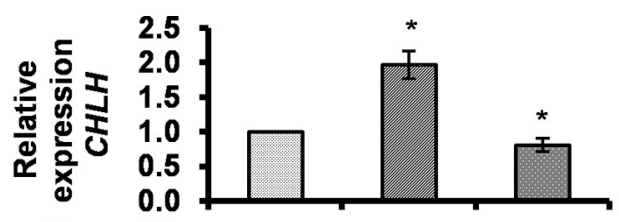

H
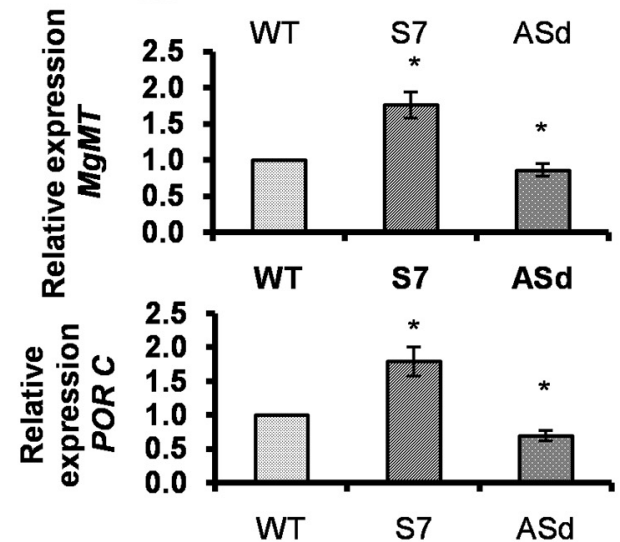

$\mathbf{J}$

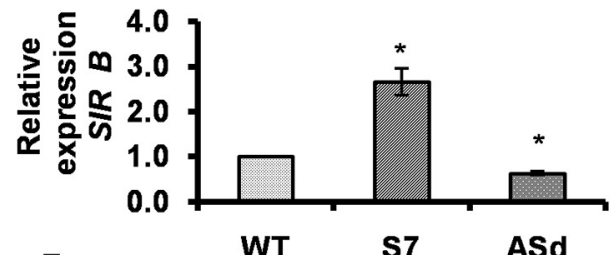

$\mathbf{K}$

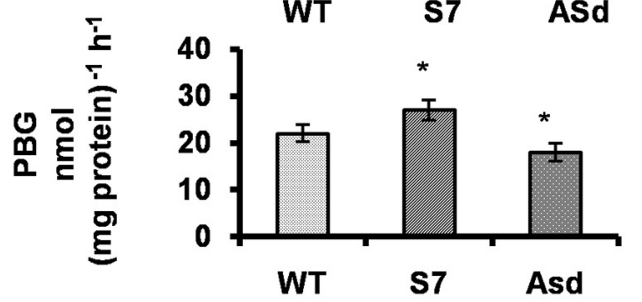

$\mathbf{L}$

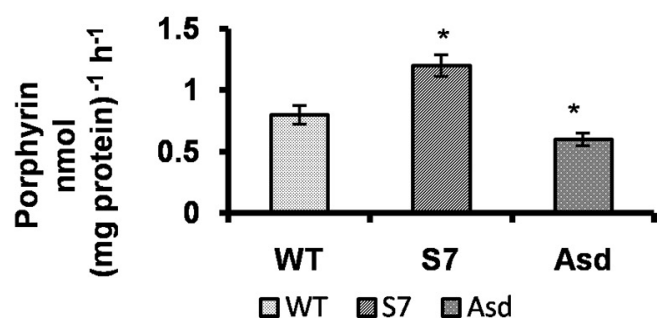

FIGURE 4 | Analysis of the transcript abundance of nuclear genes encoding the enzymes involved in the tetrapyrrole biosynthesis. The relative gene expression of (A) PBGS (B) PBGD (C) UROS (D) UROD (E) CPOX (F) PPOX (G) CHLH (H) MgMT (I) PORC (J) SIRB (K) PBGS, and (L) PBGD enzyme activities in leaves of WT and transgenic plants. Transcript levels were calculated as relative expression $\left(2^{-\Delta \Delta C T}\right)$ according to Livak and Schmittgen (2001) in comparison to WT and Actin2 as a reference gene. Data are given as means and SD of three biological replicates. WT, AtUPM1x and antiUPM1 transgenic plants were photoperiodically $(14 \mathrm{~h} \mathrm{~L}$ and $10 \mathrm{~h} \mathrm{D}$ ) grown in MS plates for 25 days under cool-white fluorescent light at $21^{\circ} \mathrm{C}$. Data are expressed as the mean \pm SEM of three independent experiments performed in triplicate. Asterisks indicate significant difference determined by Student's $t$ test compared to control $\left({ }^{*} P<0.05\right)$.

and decreased by $18 \%$ in ASd, the antisense plant (Figure 4K).

Porphobilinogen Deaminase: PBGD, in concert with uroporphyrinogen III synthase (UROS), converts four molecules of PBG to uroporphyrinogen III (Tanaka and Tanaka, 2007). As compared to that in the WT, the PBGD activity increased by $50 \%$ in S7 plants and decreased by $25 \%$ in ASd plants (Figure $4 \mathrm{~L}$ ).
The Gene Expression of AtSIRB, the Other

\section{Known Enzyme Involved in Siroheme} Biosynthesis, Is Co-regulated by AtUPM1

The abundance of message of sirohydrochlorin ferrochelatase (AtSIRB), an enzyme downstream of UPM1 in the siroheme biosynthetic pathway, is found to be coregulated with AtUPM1 in our study. Our experiments on the qRT-PCR 
showed that the overexpression of AtUPM1 results in increased transcript abundance of AtSIRB in S7 by 2.5fold. However, in ASd the message abundance decreased (Figure 4J).

\section{Chlorophyll a Fluorescence, Photosynthetic Performance, and Plant Productivity of the Transgenic Plants Chlorophyll a Fluorescence}

When a photosynthetic organism, kept in dark, is exposed to light, Chl fluorescence rises from a low minimum level ("O" level or Fo) to a higher maximum level ("P" level or Fm). The maximum primary photochemical efficiency of PSII was estimated from Fv/Fm, where $\mathrm{Fv}=\mathrm{Fm}$-Fo (Papageorgiou and Govindjee, 2004).

\section{Fo}

The minimal fluorescence, Fo, increased in S4, S6, S7, and S9 (sense lines) by18, 20,21, and 25\%, respectively over that of WT (Table 1). This increase in minimal fluorescence was mostly due to increase in the amount of Chl (Figure 3) in different transgenic lines. In the antisense lines (ASa and ASd) the Fo declined by 3-9\% mostly due to their reduced Chl content.

\section{Fv/Fm ratio}

The Fv/Fm ratio of the dark adapted plants reflects the potential quantum efficiency of PSII, which affects overall photosynthetic efficiency of plants. The overexpression lines had higher $(0.80-$ 0.82 ) and underexpressor plants had lower (0.75-0.76) Fv/Fm ratio than that of WT (0.78) (Table 1); this could imply better performance of the sense plants over the others.

\section{Electron transport rate}

As expected, the electron transport rate (ETR), as inferred from fluorescence data (for details, see section Materials and Methods) increased in response to photosynthetic active radiation (PAR) ( $\mu \mathrm{mol}$ photons $\mathrm{m}^{2} \mathrm{~s}^{-1}$ ) (Figure 5A). These light response curves demonstrate that electron transport rates (in $\mu \mathrm{mol}$ electrons

TABLE 1 | Chl a fluorescence parameters of WT and transgenic plants.

\begin{tabular}{lll}
\hline Plant line & \multicolumn{2}{c}{ Chl a fluorescence } \\
\cline { 2 - 3 } & Fo & Fv/Fm \\
\hline WT & $0.0472 \pm 0.001$ & $0.784 \pm 0.011$ \\
S4 & $0.0556 \pm 0.002$ & $0.792 \pm 0.011$ \\
S6 & $0.0566 \pm 0.003$ & $0.795 \pm 0.010$ \\
S7 & $0.0572 \pm 0.002$ & $0.811 \pm 0.012$ \\
S9 & $0.0589 \pm 0.001$ & $0.821 \pm 0.014$ \\
Asa & $0.0512 \pm 0.002$ & $0.761 \pm 0.011$ \\
Asd & $0.0483 \pm 0.003$ & $0.748 \pm 0.013$
\end{tabular}

Leaves from wild-type and AtUPM1x and antiAtUPM1 plants were dark adapted for 20 min before measurement of their minimal fluorescence (Fo) and maximum primary photochemical efficiency (Fv/Fm) by a PAM 2100 fluorometer. The experiment was repeated three times, and the values are means $\pm S D(n=5)$. $\mathrm{m}^{-2} \mathrm{~s}^{-1}$ ) for the transgenic lines under limiting light (10$50 \mu \mathrm{mol}$ photons $\mathrm{m}^{-2} \mathrm{~s}^{-1}$ ), as well as under saturating light, were substantially higher than the WT. At the saturating light intensity, the S4, S6, S7, and S9 lines had 10-22\% higher ETR than the WT. In antisense plants, ETR was downregulated by $16 \%$ (Figure 5A).

\section{Non-photochemical quenching (NPQ)}

The non-photochemical quenching (NPQ), of the excited state of chlorophyll $a$, is a good indicator of dissipation of excess light energy absorbed by plants, algae and cyanobacteria (DemmigAdams et al., 2014). At saturating light intensity, the NPQ of several AtUPM1x transgenic lines was $8-24 \%$ lower than the WT. In contrast, in the antisense lines, the NPQ was higher (15-22\%) than the WT (Figure 5B). These data clearly suggest that the sense plants would perform better than the antisense plants.

\section{Carbon Assimilation}

Since the ETR was higher in the sense transgenic plants than the WT, we expected increased rates of photosynthesis. We monitored the light response curves of $\mathrm{CO}_{2}$ assimilation, and found that, in comparison to the WT plants, the sense transgenic lines had higher (12-14\%) carbon assimilation rate, at the highest light intensity used (Figure 5C). However, in the antisense plants, the carbon assimilation rate at saturating light intensity declined by $27 \%$ (Figure $5 \mathbf{C}$ ).

\section{Fresh Weight and Dry Weight of the Shoots}

Our data show that the sense transgenic lines grew better than the WT and had a higher biomass (Figures 5D,E). As compared to WT, the T3 generation of homozygous S7 and S9 transgenic lines had 10-16\% higher fresh weight of the shoots (Figure 5D). Further, the S7 and S9 overexpressor plants had 10-12\% higher dry weight than the WT plants (Figure 5E). On the other hand, the antisense plants had $12-25 \%$ lower fresh weight and dry weight than the WT.

\section{Responses of AtUPM1x and antiUPM1 Transgenic Plants to Nitrogen Deficiency}

The results obtained under normal growth conditions (see section Materials and Methods) demonstrated that AtUPM1overexpressor sense plants had better $\mathrm{N}$ assimilatory capacity and the underexpressor antisense plants had lower $\mathrm{N}$-utilization ability (Figure 2). Therefore, the transgenic plants were tested under nitrogen starvation conditions to assess their tolerance to $\mathrm{N}$-deficiency. As the representative lines for these studies, we chose the sense S7 as it had the highest nitrate reductase and nitrite reductase activities, and antisense ASd as it had the lowest activities of these enzymes.

\section{Plant Phenotype under Nitrogen Starvation Conditions}

Under $\mathrm{N}$ deficiency $(10 \% \mathrm{~N})$, the phenotype of WT plants was different from that of the overexpressors. The AtUPM1x plants were greener and bigger in size than those of the WT and had fewer pale leaves. The antisense plants were smaller in size 

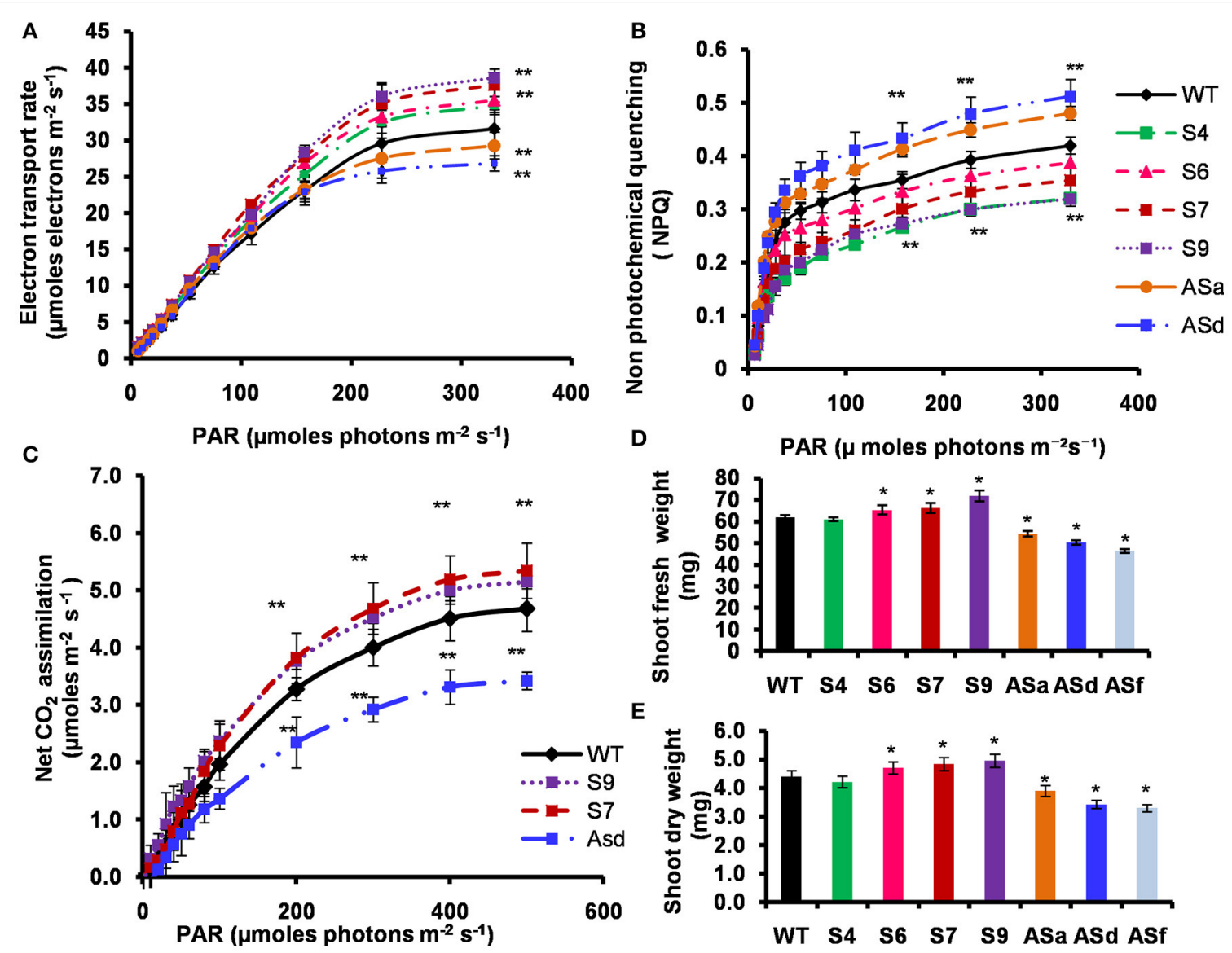

FIGURE 5 | Light response curves of PSIl-dependent electron transport, non-photochemical quenching (NPQ), net photosynthetic $\mathrm{CO}_{2}$ assimilation, shoot fresh weight and dry weight of the WT and transgenic plants. The WT and transgenic plants were grown photoperiodically ( $14 \mathrm{~h} \mathrm{~L}$ and $10 \mathrm{~h} \mathrm{D}$ ) in MS plates for 25 days under cool-white fluorescent light at $21^{\circ} \mathrm{C}$ for $\mathrm{Chl}$ a fluorescence measurements. For IRGA measurements, the plants were grown in similar photoperiodic conditions for 5 weeks in agropeat and vermiculite mixture under cool-white fluorescent light at $21^{\circ} \mathrm{C}$. (A) PSII-dependent electron transport rates of leaves in limiting and saturating actinic light intensities measured using a PAM 2100 fluorometer (Walz). (B) Non-photochemical quenching (NPQ) of excited states of chlorophylls of leaves in limiting and saturating actinic light intensities measured using a PAM 2100 fluorometer (Walz). (C) Light response curve of $\mathrm{CO}_{2}$ assimilation rates measured by infra-red gas analyser. Net $\mathrm{CO}_{2}$ assimilation rates of attached leaves of wild-type and transgenic plants were monitored with an infrared gas analyzer (Walz GFS-3000 portable photosynthetic system) in ambient $\mathrm{CO}_{2}$ at different light intensities. Light-response curves were measured up to $500 \mu \mathrm{mol}$ photons $\mathrm{m}^{-2} \mathrm{~s}^{-1}$ at $25^{\circ} \mathrm{C}_{\text {. }}$ (D) Shoot fresh weight and (E) shoot dry weight of 25 days old MS grown plants under similar growth conditions. The experiments were repeated three times. Five biological replicates were taken for experiments (A-C). Ten biological replicates were taken for (D,E). Error bars, S.D. Asterisks indicate significant differences determined by Student's $t$-test compared to control $\left({ }^{\star} P<0.05,{ }^{\star \star} P<0.01\right)$.

and there was a marked discoloration of leaves (Figure 6A and Supplementary Figure 3).

\section{$\mathrm{NO}_{3}^{-}$Assimilatory Enzyme Activities Were Higher in AtUPM1x Plants under $\mathrm{N}$-deficient Condition}

Under N-deficient growth conditions $(10-50 \% \quad \mathrm{~N})$, the overexpressor sense plants had $17-23 \%$ higher NiR activity and the antisense plants had $20-23 \%$ lower activity than the WT (Figure 6C). The substrate for $\mathrm{NiR}$, i.e., $\mathrm{NO}_{2}^{-}$is produced by $\mathrm{NR}$, the first enzyme of the nitrogen assimilation pathway. The NR activity of the sense plants was higher than that of the WT under $\mathrm{N}$ starvation conditions. When grown under $10-50 \% \mathrm{~N}$, the sense transgenic (S7) plants had $36-38 \%$ higher
NR activity, whereas antisense transgenic (ASd) had lower (16-18\%) activity of the same enzyme than the WT plants (Figure 6D).

\section{The Overexpressors Retained More Protein and Chlorophyll during Nitrogen Starvation}

For the following studies, the plants (WT, S7, and ASd) were first grown in $\mathrm{N}$ sufficient $(100 \% \mathrm{~N})$ (normal $\mathrm{MS}$ ) conditions and then transferred to $\mathrm{N}$-deficient (50,25, and $10 \% \mathrm{~N}$ ) growth conditions, as described under Material and Methods. We measured both the protein and the chlorophyll content in these samples under different nitrogen conditions.

Our results on plants grown under 10, 25, 50, and $100 \%$ $\mathrm{N}$ showed that the protein content was higher by $17-20 \%$ in 


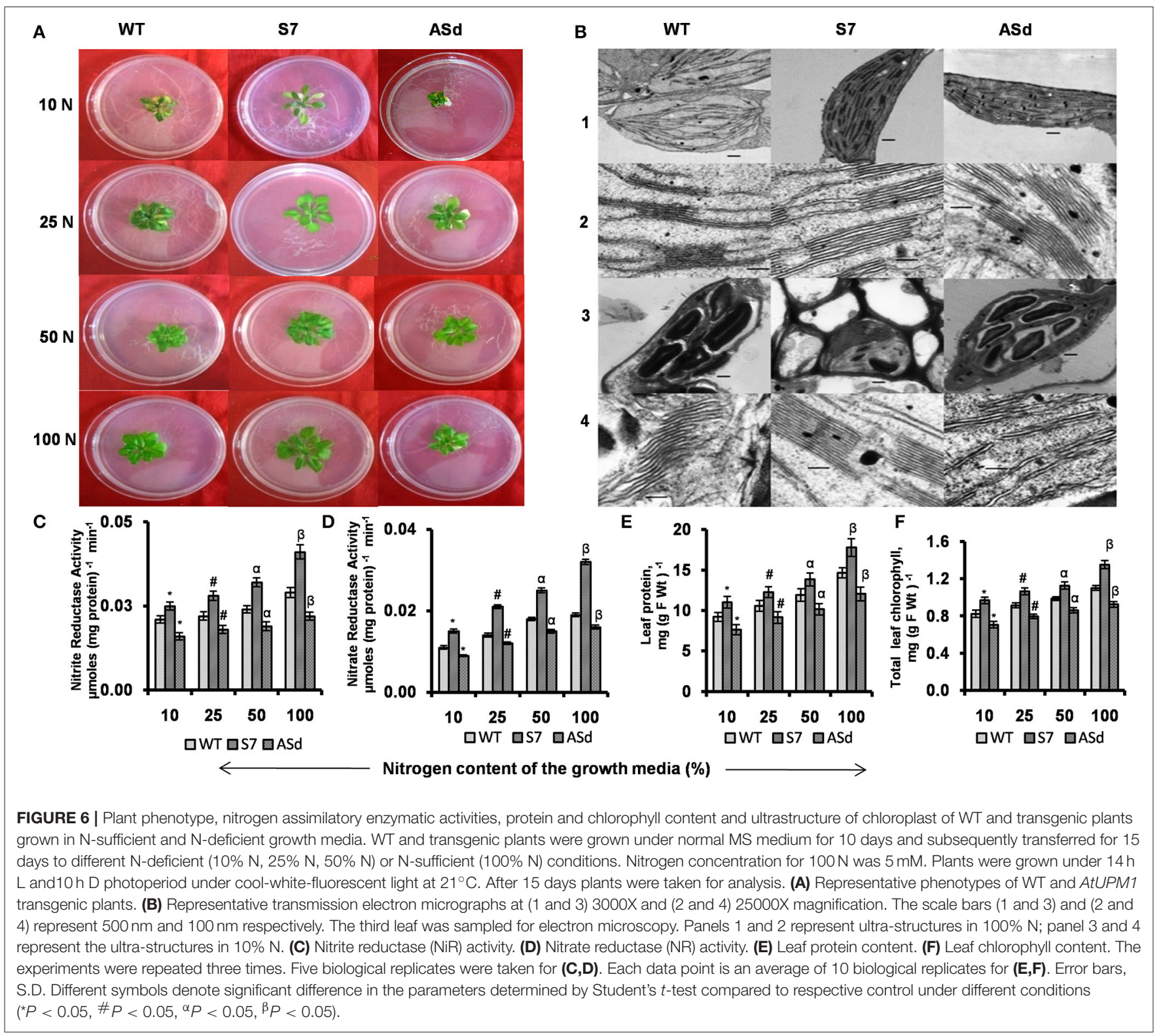

the overexpressor plants, and lower by $15-18 \%$ in the antisense plants, as compared to that of WT (Figure 6E).

Our results on the chlorophyll content showed a decline in the $\mathrm{WT}$ and the transgenics due to $\mathrm{N}$ deficiency (Figure 6F).Under $50-90 \%$ N-deficient conditions, the S7 plants had higher (15-17\%) and the antisense plants had lower (13-15\%) chlorophyll content than the WT.

\section{Chlorophyll a Fluorescence under Nitrogen Starvation \\ The Fo Fluorescence}

Under both the $\mathrm{N}$ sufficient and $\mathrm{N}$-starvation conditions, the minimal fluorescence Fo of overexpressors was higher than in the WT. However, the antisense plants had lower Fo than the WT (Table 2).

\section{The Fv/Fm Ratio}

Our results show that the overexpression line S7 had a higher $\mathrm{Fv} / \mathrm{Fm}$ ratio under control and under all $\mathrm{N}$ deficiency conditions than the WT. On the other hand, the antisense plants had a lower ratio than the WT (Table 2 ).

\section{Electron Transport Rate, as Inferred from Chl a Fluorescence}

The electron transport rate (ETR) was estimated under the nutrient stress conditions for the WT, sense (AtUPM1x) and antisense (antiUPM1) plants. The sense plants had a higher estimated electron transport rate at saturating light intensities: at $10,25,50$, and $100 \%$ nitrogen, the rates were $23-41 \%$ higher than in the WT. However, in the antisense plants, the estimated ETR was lower (15-40\%) than in the WT under N-starvation conditions (Figures 7A-D). 
TABLE 2 | Chl a fluorescence parameters of WT and transgenic plants grown in N starvation conditions.

\begin{tabular}{|c|c|c|c|c|c|c|c|c|}
\hline \multirow[t]{3}{*}{ Plant type } & \multicolumn{8}{|c|}{$\mathrm{N}_{2}$ content $(\%)$} \\
\hline & \multicolumn{2}{|c|}{100} & \multicolumn{2}{|c|}{50} & \multicolumn{2}{|c|}{25} & \multicolumn{2}{|c|}{10} \\
\hline & Fo & Fv/Fm & Fo & Fv/Fm & Fo & Fv/Fm & Fo & Fv/Fm \\
\hline WT & $0.0613 \pm 0.003$ & $0.763 \pm 0.006$ & $0.0565 \pm 0.004$ & $0.694 \pm 0.011$ & $0.0528 \pm 0.004$ & $0.688 \pm 0.009$ & $0.0515 \pm 0.004$ & $0.68 \pm 0.006$ \\
\hline S7 & $0.0691 \pm 0.003$ & $0.783 \pm 0.015$ & $0.0672 \pm 0.005$ & $0.754 \pm 0.023$ & $0.0627 \pm 0.004$ & $0.738 \pm 0.029$ & $0.0606 \pm 0.002$ & $0.725 \pm 0.011$ \\
\hline ASd & $0.0569 \pm 0.003$ & $0.729 \pm 0.003$ & $0.0513 \pm 0.004$ & $0.657 \pm 0.003$ & $0.0474 \pm 0.003$ & $0.662 \pm 0.006$ & $0.0458 \pm 0.003$ & $0.657 \pm 0.015$ \\
\hline
\end{tabular}

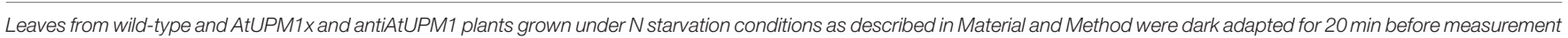

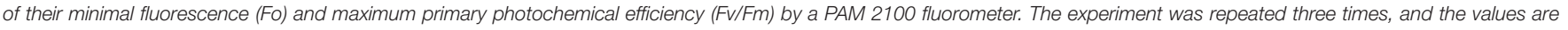
means $\pm S D(n=5)$.

\section{Non-photochemical Quenching (NPQ) under Nitrogen Starvation}

As expected, the NPQ of the excited state of chlorophyll $a$ increased with increasing light intensity. We note that $\mathrm{N}$ starvation $(10 \% \mathrm{~N})$ increased NPQ in the WT by $50 \%$; however, under 10,25 , and $50 \% \mathrm{~N}$, the sense (AtUPM1x) plants had lower (upto 33\%) NPQ, whereas, the antisense (antiUPM1) plants had higher NPQ (upto 13\%) than the WT (Figure 7E through Figure $7 \mathrm{H}$ ).

\section{Transmission Electron Microscopy (TEM) of the WT and AtUPM1 Transgenics under Nitrogen Starvation}

At $100 \% \mathrm{~N}$, which is the optimum nutrient condition, the WT, the AtUPM1x (S7) and the antiUPM1 (ASd) are similar in their granal organization and thylakoid architecture, as visualized by TEM (Figure 6B). However, major differences were observed when the plants were grown under $\mathrm{N}$ starvation. We observed that the WT and the antisense plants accumulate more starch granules than the AtUPM1x plants. The grana lamella of the WT was more destacked than that of the S7 plants. However, in the ASd plants, thylakoids were partially swollen and almost completely destacked under N-deficient media (Figure 6B).

\section{The AtUPM1 Modulates Sulfur Assimilation} Gene Expression and Protein Abundance of SiR

We note that siroheme is the prosthetic group of SiR, just as it is of NiR; it mediates ferredoxin dependent reduction of $\mathrm{SO}_{3}^{2-}$ (Murphy et al., 1974). Here, we have monitored the impact of AtUPM1 overexpression on $S i R$ gene expression as well as on protein abundance in WT, and in both sense (S7) and antisense (Asd) plants. The q-RT PCR results showed that, as compared to the WT, the sense line S7 had 2.5-fold higher, and the antisense line Asd had 30\% lower expression of SiR (Figure 8A). Further, as revealed from the western blot analysis, the relative amount of SiR, as compared to the wild type, increased by $34 \%$ in the sense plant and decreased by $21 \%$ in the antisense plant (Figures 8B,C).

\section{The Overexpressors Had More Cysteine and Methionine Content than the WT and Antisense Plants}

Among $S$ containing amino-acids, the cysteine content was $40 \%$ higher and 31\% lower, in AtUPM1x-S7 and antiUPM1-Asd transgenic lines than the WT (Figure 8D). In addition, the total methionine content increased by $29 \%$ and decreased by $10 \%$ in the sense and antisense plants, respectively (Figure 8E).

\section{Response of AtUPM1x and antiUPM1 Transgenic Plants to Sulfur Deficiency}

Our results showed that AtUPM1 sense plants had higher, and the antisense plants had lower $\mathrm{SiR}$ gene expression and $\mathrm{SiR}$ protein (Figure 8A). This must have led to better $\mathrm{S}$ assimilation resulting in higher cysteine and methionine content in the sense plants. We discuss below our studies on S deficiency in WT, sense and antisense plants.

\section{Plant Phenotype}

The WT, sense line S7 and antisense line ASd were first grown in S sufficient $(100 \%$ S) conditions, and then transferred to S-deficient (10\% S) conditions. In S deficient conditions, the AtUPM1x plants were comparatively greener and looked bigger than the WT and antisense plants (Figure 9A).

\section{The Overexpressors (Sense Plants) Retained More Protein and $\mathrm{Chl}$ under S-starvation}

The total soluble leaf protein was estimated in S-sufficient and S-deficient growth conditions. The AtUPM1x had 25\% higher and antisense plants had $17 \%$ lower protein content than the WT under optimal (100\% S) growth condition (Figure 9B). Under S starvation (10\% S) the sense plants had a higher (17\%) and antisense plants had lower (20\%) protein content than the WT (Figure 9B). We note that under S-deficient conditions, the sense plants had higher (19\%), and the antisense plants lower (13\%) chlorophyll content than the WT plants (Figure 9C).

\section{Chlorophyll a Fluorescence under S-starvation}

To understand the impact of S starvation on photosynthesis, the photosynthetic performance, as inferred from chlorophyll a fluorescence measurements of WT and transgenic plants was studied under S-sufficient and S-deficient growth conditions.

Fo

In S-deficient media, the Fo, the minimum fluorescence, of the sense plants was $10 \%$ higher and that of antisense plants was $20 \%$ lower than the WT (Table 3). 

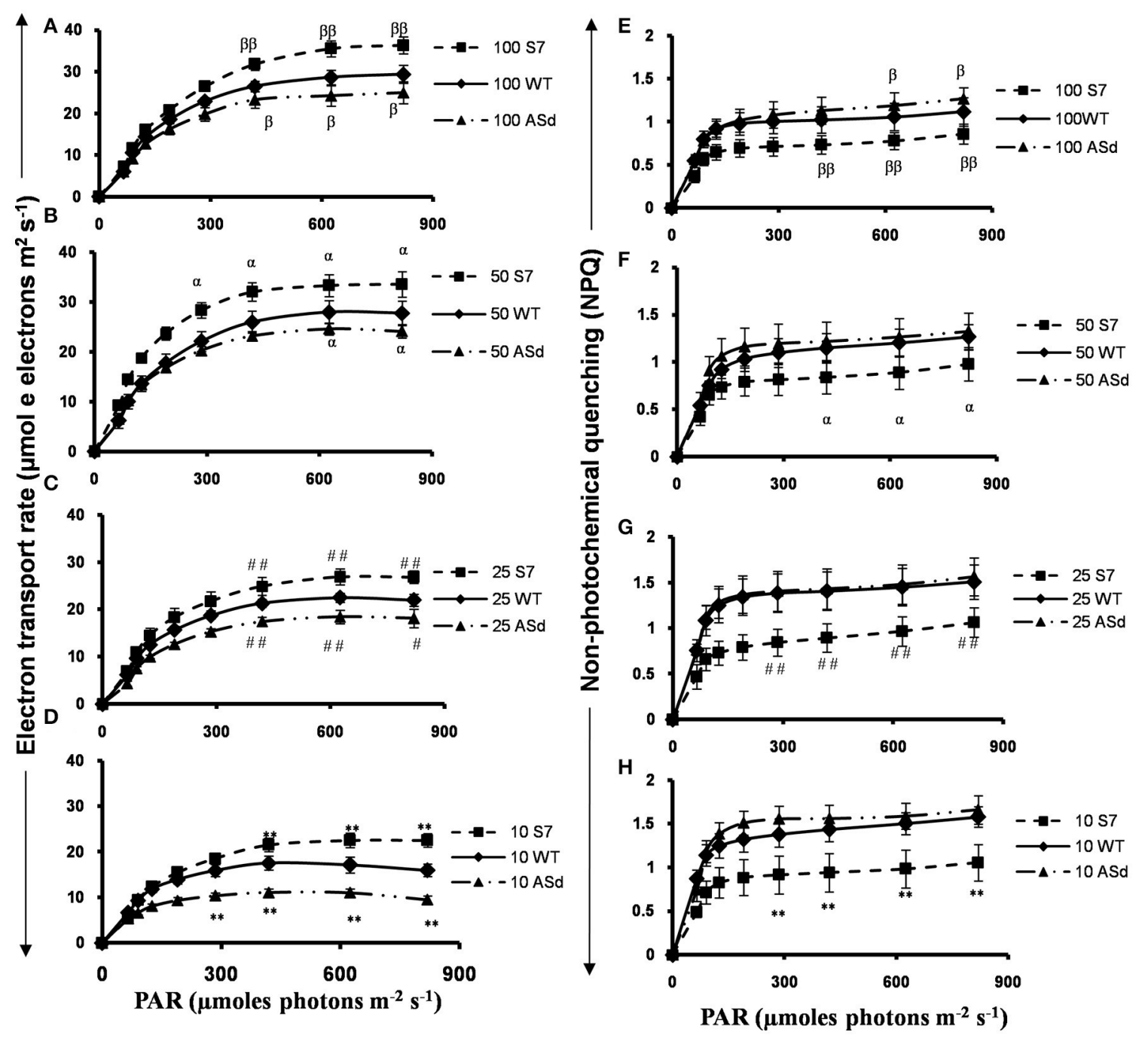

FIGURE 7 | Pulse Amplitude Modulated (PAM) Chl a fluorescence measurements in WT and AtUPM1 overexpressor and antisense plants grown in N-sufficient and $\mathrm{N}$-deficient growth media. WT and AtUPM1 transgenic plants were grown in normal MS medium for 10 days and subsequently transferred for 15 days to different $\mathrm{N}$-deficient or $\mathrm{N}$-sufficient conditions (10,25,50, and $100 \mathrm{~N}$ correspond to percentage of nitrogen in the growth media, respectively). Nitrogen concentration for $100 \mathrm{~N}$ was $5 \mathrm{mM}$. Plants were grown in $21^{\circ} \mathrm{C}$ under $14 \mathrm{~h}$ Land $10 \mathrm{~h} \mathrm{D}$ photoperiod under cool-white-fluorescent light at $21^{\circ} \mathrm{C}$. After 15 days of growth in $\mathrm{N}$-deficient media plants were taken for measurements of electron transport rate and non-photochemical quenching. Electron transport rates in plants in (A) $100 \% \mathrm{~N}$, (B) $50 \% \mathrm{~N}$, (C) $25 \%$ N, (D) $10 \%$ N. Non-photochemical quenching of excited states of chlorophyll (E) $100 \%$ N, (F) $50 \%$ N, (G) $25 \%$ N, and (H) $10 \%$ N. The experiments were repeated three times with similar results. Each data point is an average of five biological replicates. Error bars, S.D. Different symbols denote significant difference in the parameters determined by Student's $t$-test compared to respective control. $\left(\# P<0.05\right.$, ${ }^{\alpha} P<0.05,{ }^{\beta} P<0.05$ : ${ }^{\star \star} P<0.01,{ }^{\# \#} P<0.01$, and $\left.{ }^{\beta \beta} P<0.01\right)$.

\section{$F v / F m$}

In AtUPM1x plants, the Fv/Fm ratio, an indirect measure of quantum yield of PSII, was marginally higher (5\%) than that of WT grown under sulfur starvation. On the other hand, the Fv/Fm ratio declined by $7 \%$ in antiUPM1 plants (Table 3 ).

\section{Electron transport rate (ETR)}

Under optimal growth conditions, and under saturating light, the ETR, as inferred from chlorophyll $a$ fluorescence data, of the sense plant was $15 \%$ higher and that of antisense plants was $7 \%$ lower than that in the WT. Under S starvation condition, the ETR of AtUPM1x plants under saturating light intensities was $19 \%$ higher than in the WT, whereas in antiUPM1 plants, the ETR decreased by 15\% (Figures 9D,E).

\section{Non-photochemical quenching (NPQ)}

The NPQ of chlorophyll excited state increased in response to higher light intensities. In contrast to ETR, under normal growth condition, in saturating light intensity, the NPQ of the sense plant was $20 \%$ lower than that in the WT plant, and that of antisense plants was about $16 \%$ higher. Under sulfur starvation, the NPQ of AtUPM1x plants was 21\% lower than that of WT, whereas in antiUPM1 plants, the same increased by $18 \%$ (Figures 9F,G). 

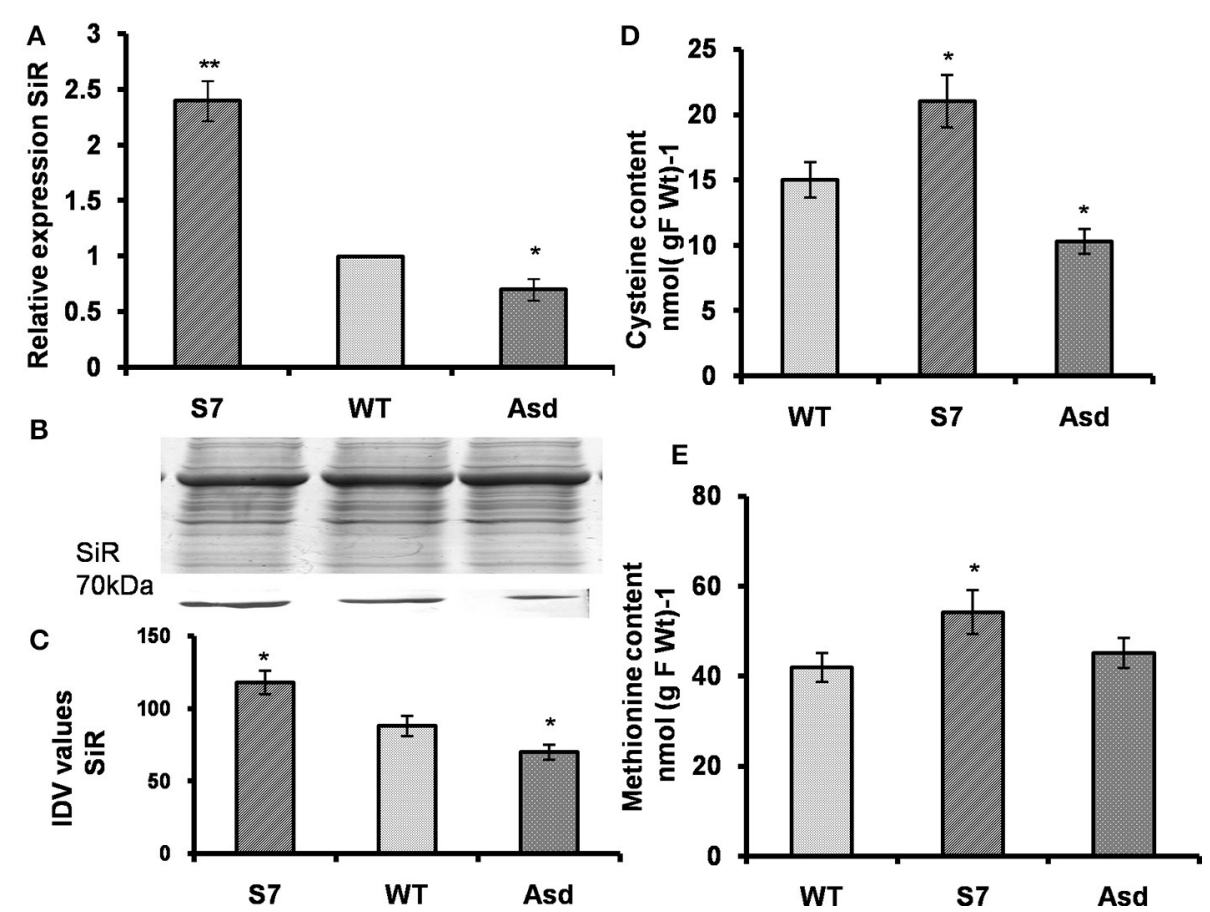

FIGURE 8 | AtUPM1 modulates sulfur assimilation. The WT and transgenic plants were grown photoperiodically (14h L and $10 \mathrm{~h}$ D) in MS plates for 25 days under cool-white fluorescent light at $21^{\circ} \mathrm{C}$. (A) The changes in gene expression of sulfite reductase (SiR) in transgenics monitored by qRT PCR. (B) SDS-PAGE (12.5\%) of protein $(20 \mu \mathrm{g})$ isolated from the WT and transgenic plants to check equal loading and immunoblot of plant protein to check the abundance of sulfite reductase (SiR). (C) Quantification of the SiR blot by densitometric analysis using Alpha Ease FC software. (D) Cysteine content of leaves. (E) Methionine content of leaves. Western blot was repeated three times and data is an average of three independent replicates. qRT-PCR data are expressed as the mean \pm SEM of three independent experiments performed in triplicate. Each data point for (D,E) is an average of three biological replicates, performed three times. Error bars, S.D. Asterisks indicate significant difference determined by Student's $t$-test compared to control $\left({ }^{\star} P<0.05,{ }^{* \star} P<0.01\right)$. IDV values represent integrated density values as calculated by the Alpha Ease FC software.

\section{DISCUSSION}

In the present study, genetic manipulation of tetrapyrrole biosynthesis pathway, which governs carbon, nitrogen and sulfur assimilation, has given us an insight on the co-regulation of these three different but inter-dependent biological processes. The first tetrapyrrole of $\mathrm{Chl}$ biosynthesis pathway, i.e., uroporphyrinogen III is shown in this paper to be partially hijacked via over-expression of uroporphyrinogen III methyl transferase (AtUPM1) in A. thaliana to synthesize more siroheme, the cofactor required for activity of $\mathrm{NiR}$ and $\mathrm{SiR}$. The Southern blot analysis of AtUPM1 in WT and transgenic plants revealed that A. thaliana has a single copy of the gene. The sense lines S7, S8, and $\mathrm{S} 9$ and antisense lines ASa and Asd had the single integration of the transgene (Supplementary Figure 2). Overexpression of AtUPM1 under the control of constitutive ${ }_{35} \mathrm{~S}$ promoter resulted in increased expression of the gene and the gene product in the sense plants and their reduced expression in antisense plants. We found that the abundance of the message of sirohydrochlorin ferrochelatase $(S I R B)$, which functions downstream to UPM1 in the siroheme biosynthesis pathway, was coregulated with AtUPM1. SIRB expression increased in At UPM1x plants and decreased in antisense plants.Increased abundance of UPM1 and SIRB, enzymes working in siroheme biosynthesis pathway, is likely to enhance siroheme content in AtUPM1x transgenic plants. In the same vein, in the antisense plants the siroheme content is likely to be lower.

\section{Modulation of N Assimilation by UPM1}

Siroheme biosynthesis takes place in chloroplasts as all the enzymes, involved in siroheme biosynthesis, occur in the stroma (Tripathy et al., 2010). Increased amount of cofactor siroheme, present in chloroplasts, might have induced the enhancement of the nuclear genes expression of NII coding for NiR by retrograde signaling (Oelmüller et al., 1986; Mochizuki et al., 2001; Schlicke et al., 2014; Zhou et al., 2015; Pattanayak and Tripathy, 2016). However, the exact chemical nature of the molecule(s) responsible for retrograde signaling is still unknown. A report suggests that the overexpression of $G m C n x 1$, responsible for increasing the biosynthesis of molybdenum cofactor, results in higher NR activity in transgenic soybean plants (Zhou et al., 2015). This demonstrates that specific cofactors may modulate the gene expression of the apoproteins. We suggest that increased expression of nitrite reductase (NII), led to the increase in $\mathrm{NiR}$ protein abundance and enzymatic activity in different overexpressor lines, used in our study. In contrast, reduced siroheme accumulation in chloroplasts of antisense plants could have given a negative feedback for lower nuclear NII gene 


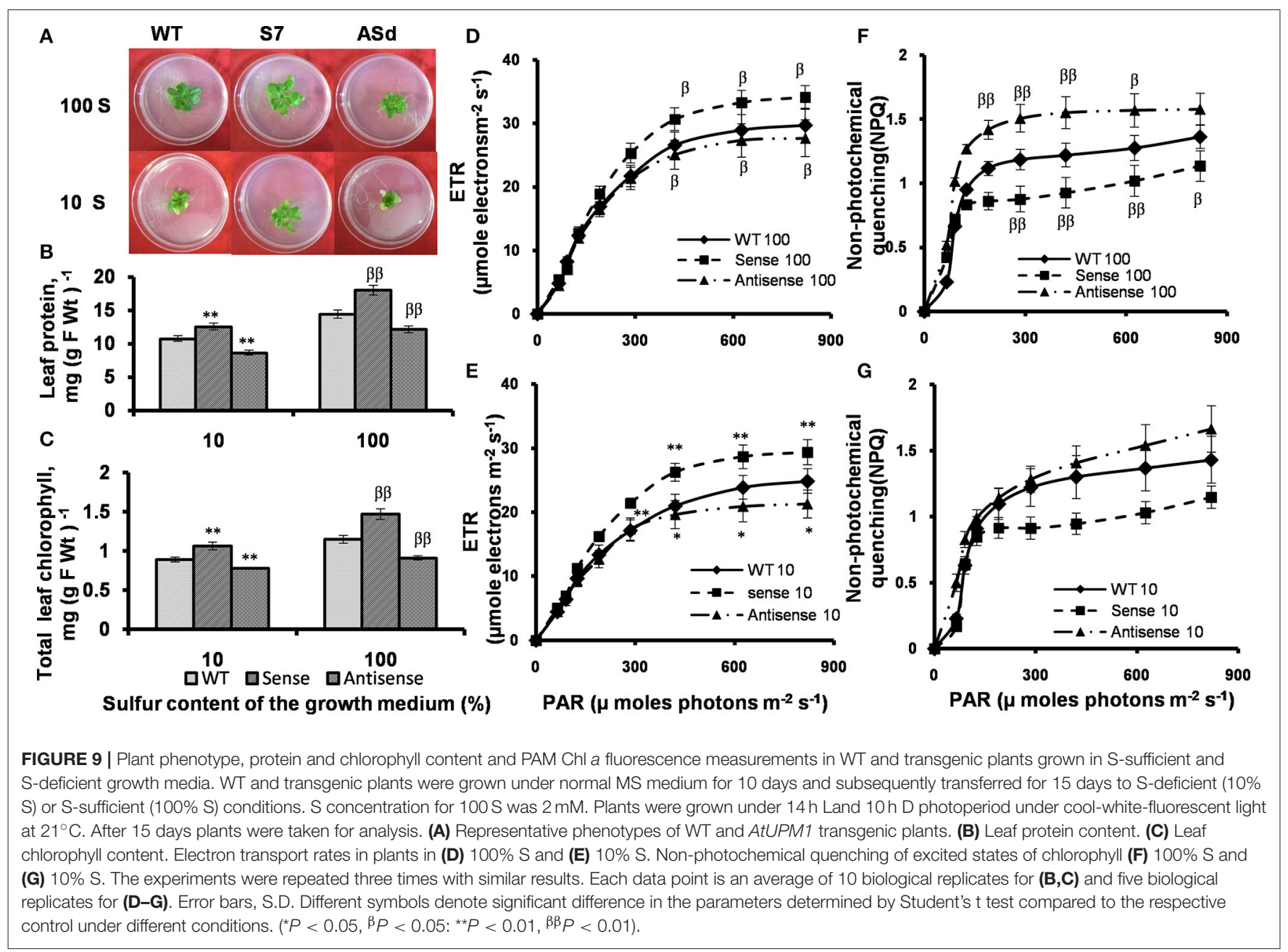

expression than that in WT plants. Lower NII gene expression, NIR protein abundance and enzymatic activity were clearly observed in different antisense lines (Figure 2). The substrate of $\mathrm{NiR}$ is produced by $\mathrm{NR}$ that reduces $\mathrm{NO}_{3}^{-}$to $\mathrm{NO}_{2}^{-}$in the cytoplasm. The NIA2 has predominant expression in A. thaliana (Wilkinson and Crawford, 1991). The other gene NIA1 encodes the cytosolic minor isoform of NR and contributes about $10 \%$ of the total activity in shoots (Wilkinson and Crawford, 1991). The comodulation of NIA2 expression in AtUPM1overexpressors resulted in upregulation of protein abundance and activity of $\mathrm{NR}$ (Figure 2). This must have replenished the $\mathrm{NO}_{2}^{-}$consumed by elevated NiR activity in the sense plants (Seligman et al., 2008; Zhao et al., 2009). Our results (Figure 2) demonstrate that modulation of genes involved in the synthesis of the cofactor of one of the enzymes involved in $\mathrm{N}$ assimilation regulates the gene expression of other enzymes of $\mathrm{N}$ assimilatory pathway. The prosthetic group siroheme could be a limiting factor in $\mathrm{N}$ assimilation and its improved synthesis in AtUPM1x plants may be crucial in NiR assembly and activity.

A significant finding in our study (this paper) was the increase of total protein content in the AtUPM1 overexpressors (Figure 3). This increase could be attributed to higher $\mathrm{N}$ assimilatory enzymatic activities in the plant cell. The higher total protein content of AtUPM11x transgenic plants implies an increase in both structural and functional protein components of the cell. The overexpression of uroporphyrinogen III methyl transferase is expected to lead to an increase in siroheme levels, which must help in $\mathrm{N}$ assimilation in the form of enhanced $\mathrm{NH}_{4}^{+}$ generation (Figure 1). We suggest that the ammonium generated must have been efficiently utilized by the overexpressors for amino acid and protein synthesis (Figure 3). Therefore no $\mathrm{NH}_{4}^{+}$ toxicity was observed in overexpressors. Similarly, the efficient reduction of sulfite to sulfide by sulfite reductase must have resulted in an increase in the levels of $S$ containing amino acids i.e., cysteine and methionine. Therefore no sulfide-induced toxicity was observed in the overexpressors (sense plants) (Figure 8).

Earlier studies with over-expression of $\mathrm{NiR}$ apoprotein under the control of $35 \mathrm{~S}$ promotor in N. plumbaginifolia and A. thaliana did not show any increase in total protein content in the transgenics (Crété et al., 1997; Takahashi et al., 2001). Similarly, other enzymes involved in $\mathrm{N}$ assimilation i.e., NR, GS2, GOGAT or nitrate transporters in different plants did not result in increased protein content of plants (Vincentz and 
TABLE 3 | Chl a fluorescence parameters of WT and transgenic plants grown in S starvation conditions.

\begin{tabular}{lccccc}
\hline \multirow{2}{*}{ Plant type } & \multicolumn{5}{c}{ S content (\%) } \\
\cline { 2 - 5 } & \multicolumn{2}{c}{100} & & \multicolumn{2}{c}{10} \\
\cline { 2 - 5 } \cline { 5 - 6 } & Fo & Fv/Fm & Fo & Fv/Fm \\
WT & $0.063 \pm 0.002$ & $0.804 \pm 0.012$ & $0.058 \pm 0.003$ & $0.751 \pm 0.021$ \\
S7 & $0.064 \pm 0.002$ & $0.806 \pm 0.009$ & $0.063 \pm 0.003$ & $0.787 \pm 0.013$ \\
ASd & $0.061 \pm 0.004$ & $0.761 \pm 0.007$ & $0.047 \pm 0.001$ & $0.699 \pm 0.017$ \\
\hline
\end{tabular}

Leaves from wild-type and AtUPM1x and antiAtUPM1 plants grown under S starvation conditions as described in Material and Methods were dark adapted for 20 min before measurement of their minimal fluorescence (Fo) and maximum primary photochemical efficiency (Fv/Fm) by a PAM 2100 fluorometer. The experiment was repeated three times, and the values are means $\pm S D(n=5)$.

Caboche, 1991; Kozaki and Takeba, 1996; Ferrario-Méry et al., 2002). The NR has long been considered to be the rate-limiting step in nitrate assimilation and is subjected to transcriptional and post translational regulation by environmental factors such as light, $\mathrm{CO}_{2}$, oxygen availability as well as the redox state of the cell (Huber et al., 1994; Kaiser and Huber, 1994). Efforts to improve nitrogen utilization by over-expressing NIA2 coding for NR in tobacco and potato did not result in significant change in protein or biomass accumulation (Quilleré et al., 1994; Djennane et al., 2002). Improvement in nitrogen utilization via manipulation of plastidic glutamine synthetase (GS2) and Fd-GOGAT (GLU1) has, however, met with some limited success. Transgenic tobacco plants with over-expression of GS2 were shown to have rather higher photorespiration that did not have increased protein content per g fresh weight (Kozaki and Takeba, 1996; FerrarioMéry et al., 2002; Bao A. et al., 2014). There are conflicting reports of overexpression of cytosolic GS1. The overexpression of root PsGS1 in tobacco was shown to have increased protein content, demonstrating the role of secondary metabolic processes in enhancing nitrogen utilization (Oliveira et al., 2002). However, overexpression of shoot cytosolic glutamine synthatase (OsGS1.1) and root cytosolic glutamine synthetase (OsGS1.2) in rice resulted in poor growth phenotype and yield (Bao Y. et al., 2014). Further, plants over-expressing the NpNRT2.1 gene encoding high affinity nitrate transporter were similar in protein content to their WT level, despite an increase in the $\mathrm{NO}_{3}^{-}$ uptake indicating that higher $\mathrm{NO}_{3}^{-}$influx may not necessarily lead to concomitant improvement in nitrate utilization (Fraisier et al., 2000).

Our results demonstrate that stimulation of cofactor synthesis rather than apoprotein accumulation results in improved nitrogen utilization, and increased protein content and higher biomass (Figures 2, 5). This approach for the development of nitrogen use efficient transgenic plants seems to be much more promising.

\section{Modulation of Chlorophyll Biosynthesis by UPM1}

Overexpression of UPM1 is expected to result in increased diversion of uroporphyrinogen III to siroheme biosynthesis. Therefore, we expected a reduced Chl content in AtUPM1x plants. On the contrary, Chl content increased in UPM1 overexpressors, and decreased in the underexpressors (Figure 3). This was due to increase in total protein content of AtUPM1x transgenic plants that must have contributed to a general enhancement in the abundance of enzymes involved in $\mathrm{Chl}$ biosynthesis.

Among Chl biosynthetic genes, other than UROD, the transcript abundance of PBGS, PBGD, UROS, CPOX, PPOX I, involved in the synthesis of protoporphyrin IX, was upregulated in the sense plants and down regulated in the antisense plants. In the same vein, the activities of tetrapyrrole biosynthetic enzymes increased in the overexpressors and decreased in the antisense plants (Figure 4). The UROD expression was lower in sense plants and was relatively higher in antisense plants (Figure 4) possibly because of decreased or increased availability of the substrate uroporphyrinogen III. This reveals a retrograde signaling by the plastidic tetrapyrrole to the nucleus for the regulation of $U R O D$. Further experiments are needed to ascertain the steady state concentration of uroporphyrinogen III in WT, sense and antisense plants inside and outside the chloroplast to elucidate the role of tetrapyrroles in retrograde signaling. Our results suggest that Protoporphyrin IX in sense plants was diverted to the Mg-tetrapyrrole biosynthesis pathway due to increased expression of CHLH, MgMT, and PORC (Figure 4). These suggest that even if one of the genes in the Chl biosynthesis pathway is downregulated, it can be suitably compensated by the upregulation of other genes leading to increased Chl biosynthesis. It is quite possible that UROD is not a limiting enzyme for $\mathrm{Chl}$ biosynthesis.

We have previously observed co-regulation of gene and protein expression of enzymes involved in tetrapyrrole biosynthesis where overexpression of light-inducible protochlorophyllide oxidoreductase $\mathrm{C}(P O R C)$ or chlorophyllide a oxygenase $(C A O)$ was shown to co-modulate other genes of tetrapyrrole biosynthesis and photosynthesis (Pattanayak and Tripathy, 2002, 2011; Biswal et al., 2012). Earlier observations also demonstrated that overexpression of other Chl biosynthesis pathway genes, i.e., CHLM and CHLG, co-modulate the gene expression of several other tetrapyrrole biosynthetic genes (Alawady and Grimm, 2005; Shalygo et al., 2009). Similarly, increased $\mathrm{Chl} b$ synthesis delays senescence resulting in the retention of the message abundance of several Chl biosynthetic enzymes (Sakuraba et al., 2012). These demonstrate the existence of regulatory network among the genes coding for the enzymes involved in a metabolic chain reaction.

\section{Impact of Increased Chlorophyll and Protein Content on Photosynthesis and Plant Productivity}

Chl $a$ fluorescence is often used as a non-invasive signature of photosynthesis (Strasser and Srivastava, 1995; Papageorgiou and Govindjee, 2004). Increased Chl content coupled with enhanced protein content led to a small increase in Fo in the sense plants. Further, decreased $\mathrm{Chl}$ and protein content of antisense plants resulted in reduced Fo (Table 1). As compared to that in WT, the maximum primary photochemical efficiency of PSII (as inferred 
from $\mathrm{Fv} / \mathrm{Fm}$ ) in dark-adapted leaves was higher in the sense plants and lower in antisense plants (Table 1). Increase in Fv/Fm suggests higher quantum efficiency of photosynthesis in the overexpressors.

As expected, Electron Transport Rates (ETR), calculated from yield parameters of PAM fluorometry (Genty et al., 1989), saturated at lower light intensity $\left(350 \mu \mathrm{mol}\right.$ photons $\left.\mathrm{m}^{-2} \mathrm{~s}^{-1}\right)$ from plants grown in low light $\left(80 \mu \mathrm{mol}\right.$ photons $\left.\mathrm{m}^{-2} \mathrm{~s}^{-1}\right)$. The ETR values at limiting light intensities (up to $80 \mu \mathrm{mol}$ photons $\mathrm{m}^{-2} \mathrm{~s}^{-1}$ ) in AtUPM1xplants were higher than that of WT suggesting a larger light-harvesting antenna size in the sense plants, mostly due to increased Chl content. For the calculations of ETR, as described in the section Materials and Methods (Schreiber et al., 1995), a fixed absorption of 0.84 is used, whereas the overexpressors have higher (Chl) and in all likelihood would have slightly higher absorption than 0.84 , and thus calculated ETR for sense plants is likely to be higher. AtUPM1x plants had higher $\mathrm{Chl}$ and protein and therefore recorded elevated ETR than that of WT plants in saturating light intensities. Antisense plants had reduced $\mathrm{Chl}$ and protein and therefore their ETR was lower than that of WT.

The NPQ is a measure of heat dissipation and a combined total for the combination of photo-protective mechanisms, state 1 and state 2 transition quenching, and photo-inhibition and photo-damage (Demmig et al., 1987; Demmig-Adams et al., 2014). When compared to the WT, NPQ was lower in the sense plants and higher in the antisense plants. This demonstrates that absorbed light energy was better utilized in photochemical reactions in the sense plants and had reduced utilization in the antisense plants. This resulted in higher ETR in the sense plants and lower ETR in the antisense plants.

Our data, presented in this paper clearly show that in response to UPM1 overexpression the light-saturated photosynthetic carbon assimilation on a leaf area basis was significantly higher than in the WT (Figure 5). This corresponds well to our ETR measurements. We have expressed the carbon assimilation rates on leaf area basis and not on Chl basis since photosynthetic $\mathrm{CO}_{2}$ assimilation is not always proportional to Chl content (Yoshida, 1972). Our data (Figure 3) demonstrate that stimulation of siroheme biosynthetic pathway increases $\mathrm{Chl}$ and protein content which results in higher photosynthesis and biomass. Conversely, suppression of siroheme biosynthesis pathway led to reduced protein and $\mathrm{Chl}$ content that resulted in lower ETR, $\mathrm{CO}_{2}$ assimilation and decreased biomass.

The above findings are in agreement with a previous report from our laboratory where over-expression of CAO, that increased total $\mathrm{Chl}$ and $\mathrm{Chl} b$ content, also enhanced electron transport, $\mathrm{C}$ assimilation and biomass accumulation (Biswal et al., 2012). In another report, PSII photosynthetic efficiency, carbon assimilation and dry matter accumulation increased in plants over-expressing sedoheptulose-bis-phosphatase enzyme (Lefebvre et al., 2005). Similarly, transgenic tobacco plants expressing a bifunctional cyanobacterial fructose-1,6 /sedoheptulose-1,7-bisphosphatase in chloroplasts had higher photosynthesis and dry matter production (Miyagawa et al., 2001). In our laboratory, Kandoi et al. have previously shown that the overexpression of maize phosphoenolpyruvate carboxylase
(PEPC) in A. thaliana resulted in increased photosynthesis and biomass (Kandoi et al., 2016). PEPC in C4 carbon metabolism also plays a crucial role in the nitrogen assimilation (Shi et al., 2015). Our results, presented in this paper, demonstrate that photosynthetic capacity per unit leaf area and plant dry matter could be increased in Arabidopsis thaliana by overexpressing a single chloroplastic enzyme UPM1, involved in siroheme biosynthesis. Our results further demonstrate that modulation of $\mathrm{N}$ and $\mathrm{S}$ assimilation by genetic manipulation of siroheme biosynthesis pathway could increase $\mathrm{C}$ assimilation and plant productivity.

\section{AtUPM1 Overexpression Protects Plants from Nitrogen Deficiency}

When challenged with $\mathrm{N}$ deficiency, the sense plants performed better and antisense plants were worse than WT (Figure 6). As compared to WT, the NR and NiR activities were always higher in sense plants and lower in antisense plants in $\mathrm{N}$-deficient environment; further, there was higher protein and Chl content in AtUPM1x plants, over that in WT plants, in N-depleted conditions. It is well known that light energy absorbed by $\mathrm{Chl}$ is used to drive photosynthesis (photochemistry) and excess energy can be dissipated as heat or it can be re-emitted as light i.e., as $\mathrm{Chl}$ $a$ fluorescence. These three processes compete with each other such that an increase in efficiency of one results in a decrease in the yield of the other two (Baker, 2008). Hence, by measuring the yield of chlorophyll $a$ fluorescence, information about changes in the efficiency of photochemistry and heat dissipation can be gained (Demmig-Adams and Adams, 2006; Kalaji et al., 2012). In our research, photosynthetic ETR was always higher than the WT in sense plants under $50-90 \% \mathrm{~N}$ starvation conditions. However, antisense plants had much lower ETR than the WT in N-deficient conditions. Under N starvation conditions, NPQ was lower than in the WT in sense and higher in antisense plants, demonstrating better energy utilization in the overexpressors (the sense plants) (Figures 7F,G).

The co-modulation of carbon and nitrogen assimilation is important for enhancement of nitrogen use capacity of plants (McAllister et al., 2012). The carbohydrate catabolic degradation leads to the generation of $\mathrm{C}$ skeletons that serve as precursors to amino acids such as alanine, serine, glutamate, and aspartate. Thus $\mathrm{C}$ and $\mathrm{N}$ metabolisms are tightly interlinked for plant adaptive response to any nutrient stress (Rufty et al., 1988; Doncheva et al., 2001; Bi et al., 2007). The starch content is known to increase under $\mathrm{N}$ starvation conditions, which is not due to increased starch synthesis, but rather due to lower $\mathrm{N}$ mobilization capacity in $\mathrm{N}$ deficient plants (Huber et al., 1989). The increase in starch granules in the electron micrographs of chloroplasts of WT and antisense plants and their absence from that of sense plants in Ndeficient $(10 \% \mathrm{~N})$ conditions (Figure 6B) demonstrates that AtUPM1 overexpression could potentially make plants tolerant to N-starvation.

$\mathrm{N}$-starvation leads to reduction in total fatty acids (Gaude et al., 2007) content leading to alteration in chloroplast ultrastructure. Galactolipids, associated with the chloroplast membrane system, are essential for chloroplast development. $\mathrm{N}$ 
TABLE 4 | List of primers used for qRT PCR.

\begin{tabular}{|c|c|c|}
\hline Gene & Forward primer & Reverse primer \\
\hline UPM1 & CCCAAACCCATATAAACGACAAG & GTAAGGTTTCTCACTGGTCATTA \\
\hline NII & AGCCAGTTCTGCGGACAAGC & CGTCAGCACCCTCGACTGGC \\
\hline $\operatorname{SIRB}$ & TCGCAGTTCTTAGTGAACCTCTCTTAC & GTGATCCTCTTCTCCTCCTTCCT \\
\hline PBGS & GCAAAAGAGCTACGTAGGCC & СTCTTGGAAGGCAGCTCTCT \\
\hline UROD & TGAGCTTGGACTGGACTGTG & GCCCCAAGTTGAGAATGTGT \\
\hline CPOX & GAGCTCCGAGGCAATGGT & GGATCAGGTITAACGACCGA \\
\hline PPOX & AAGCCTAATTCGACCGATCC & CCTAAGGCTACACCAGCGAC \\
\hline $\mathrm{CHLH}$ & TTCAGTAGAGTTGATTTCAGTGGC & TGGAAGCAAGTTAAATGCAGG \\
\hline MgMT & GCGTATCTACACTCGGAGGC & CATTGGAACAGCTTCGATGA \\
\hline
\end{tabular}

limitation causes a decrease in MGDG that leads to defective chloroplast development and fewer thylakoid membranes (Jarvis et al., 2000; Gaude et al., 2007). Our results demonstrate that the organization of thylakoids was affected and that they did not stack properly in N-deficient WT and in antisense plants. This could be partly due to reduced MGDG content, reduced chlorophyll and pigment protein complexes responsible for grana stacking.

\section{AtUPM1 Regulates Sulfur Assimilation}

Like NiR, SiR contains siroheme as its cofactor for 6 electron reduction of sulfite to sulfide (Murphy et al., 1974). Therefore, the increased presence of siroheme in the UPM1 overexpressors resulted in the upregulation of $S i R$ message abundance, possibly via retrograde signaling from the chloroplast to the nucleus. Consequently, the SiR protein abundance increased in UPM $1 x$ plants. We suggest that in the chloroplast of AtUPM1x plants, enhanced assembly of SiR holoenzyme efficiently must have reduced sulfite to sulfide. Cysteine synthesis from serine is known to be limited by sulfide availability. We suggest that in AtUPM1x plants, the reduction of sulfite to sulfide may have increased due to increased siroheme synthesis and SiR expression. This could possibly stimulate the synthesis of S-containing aminoacids cysteine and methionine leading to increased protein synthesis.

\section{AtUPM1 Overexpressors Are Tolerant to Sulfur Starvation}

Sulfate assimilation is tightly coordinated with the carbon and nitrogen metabolism (Koprivova et al., 2000; Nakayama et al., 2000; Kopriva et al., 2002; Leustek, 2002). Sulfate is taken up and reduced to sulfite before being assimilated (Leustek and Saito, 1999).Although plants augment sulfate assimilation from the soil in S- deficient environment, plant growth and development is negatively affected when sulfur is low.

Our study demonstrates that when grown for 15 days in S-deficient medium (10\% S), WT and antisense plants were deficient in protein and $\mathrm{Chl}$ and looked pale-green. Under $\mathrm{S}$ starvation, the protein content in antisense plants was lower than in WT A. thaliana, likely due to reduced synthesis of
$S$ containing amino acids. In the sense plants, the higher protein content may have been due to increased synthesis of cysteine and methionine. Higher availability of amino acids, including cysteine and methionine, must have increased the protein content of sense plants, which must have contributed to higher $\mathrm{Chl}$ content than in the WT and antisense plants in S deficient environment.

In optimal growth medium (100\% S), which had increased $\mathrm{Chl}$ and protein content, photosynthetic rates were higher in the AtUPM1x plants than that in WT. In contrast, due to decreased $\mathrm{Chl}$ and protein content in antiUPM1 plants, their photosynthetic efficiency was low. Further, in antisense plants, the estimated ETR was higher in AtUPM1x and lower in antisense plants in normal as well as S-deficient media in different light intensities. Finally, the NPQ of overexpressors (the sense plants) was lower than that in WT plants contributing to the advantage in their performance.

\section{CONCLUDING REMARKS}

In conclusion, the most pronounced outcome (or the highlight) of the present study is the increased protein content of AtUPM1 overexpressors (the sense plants). Further, our study suggests that it is not the apoprotein (nitrite reductase or sulfite reductase), but the cofactor (siroheme) that limits the nitrogen and sulfur utilization. Therefore, the modulation of siroheme biosynthesis pathway is a potential target for improved $\mathrm{N}, \mathrm{S}$, and $\mathrm{C}$ assimilation and increased crop productivity. This approach could be potentially used to increase protein content of crop plants that could grow in low soil $\mathrm{N}$ and $\mathrm{S}$ environment with minimal application of fertilizers.

\section{AUTHOR CONTRIBUTIONS}

BT designed the experiments: SG performed the experiments and analyzed the data: Paper was written by BT and SG. 


\section{FUNDING}

This work was supported by J C Bose Fellowship to BT from Department of Science and Technology (DST-PURSE), Government of India.

\section{ACKNOWLEDGMENTS}

We are immensely grateful to Govindjee (of the University of Illinois at Urbana-Champaign) for his comments and valuable suggestions to refine the manuscript. SG acknowledges the CSIRNET fellowship during the course of Ph.D.; she thanks Barnali Padhi, and Charanpreet Kaur for proofreading the manuscript.

\section{SUPPLEMENTARY MATERIAL}

The Supplementary Material for this article can be found online at: https://www.frontiersin.org/articles/10.3389/fpls.2017. 02265/full\#supplementary-material

Supplementary Figure 1 | Schematic representation of vector construction: Ligation of AtUPM1 in sense and antisense orientation with linearized modified

\section{REFERENCES}

Alawady, A. E., and Grimm, B. (2005). Tobacco Mg protoporphyrin IX methyltransferase is involved in inverse activation of $\mathrm{Mg}$ porphyrin and protoheme synthesis. Plant J. 41, 282-290. doi: 10.1111/j.1365-313X.2004. 02291.x

Baker, N. R. (2008). Chlorophyll fluorescence: a probe of photosynthesis in vivo. Annu. Rev. Plant Biol. 59, 89-113. doi: 10.1146/annurev.arplant.59.032607. 092759

Bali, S., Lawrence, A. D., Lobo, S. A., Saraiva, L. M., Golding, B. T., Palmer, D. J., et al. (2011). Molecular hijacking of siroheme for the synthesis of heme and $\mathrm{d}_{1}$ heme. Proc. Natl. Acad. Sci. U.S.A. 108, 18260-18265. doi: 10.1073/pnas. 1108228108

Bali, S., Palmer, D. J., Schroeder, S., Ferguson, S. J., and Warren, M. J. (2014). Recent advances in the biosynthesis of modified tetrapyrroles: the discovery of an alternative pathway for the formation of heme and heme d. Cell. Mol. Life Sci. 71, 2837-2863. doi: 10.1007/s00018-014-1563-x

Balk, J., and Schaedler, T. A. (2014). Iron Cofactor Assembly in Plants. Annu. Rev. Plant Biol. 65, 125-153. doi: 10.1146/annurev-arplant-050213-035759

Bao, A., Zhao, Z., Ding, G., Shi, L., Xu, F., and Cai, H. (2014). Accumulated Expression Level of cytosolic glutamine synthetase 1 Gene (OsGS1;1 or OsGS1;2) alter plant development and the carbon-nitrogen metabolic status in rice. PLoS ONE 9:e95581. doi: 10.1371/journal.pone.0095581

Bao, Y., Aggarwal, P., Robbins, N. E., Sturrock, C. J., Thompson, M. C., Tan, H. Q., et al. (2014). Plant roots use a patterning mechanism to position lateral root branches toward available water. Proc, Natl. Acad. Sci. U.S.A. 111, 9319-9324. doi: 10.1073/pnas.1400966111

Bi, Y. M., Wang, R. L., Zhu, T., and Rothstein, S. J. (2007). Global transcription profiling reveals differential responses to chronic nitrogen stress and putative nitrogen regulatory components in Arabidopsis. BMC Genomics 8:281. doi: 10.1186/1471-2164-8-281

Biswal, A. K., Pattanayak, G. K., Pandey, S. S., Leelavathi, S., Reddy, V. S., Govindjee, et al. (2012). Light intensity-dependent modulation of chlorophyll b biosynthesis and photosynthesis by overexpression of chlorophyllide a oxygenase in tobacco. Plant Physiol. 159, 433-449. doi: 10.1104/pp.112.195859

Bogorad, L. (1962). “[122] Porphyrin synthesis," in Methods in Enzymology, eds S. P. Colowick and N. O. Kaplan (New York, NY: Academic Press), 885-895.

Bradford, M. M. (1976). A rapid and sensitive method for the quantitation of microgram quantities of protein utilizing the principle of protein-dye binding. Anal. Biochem. 72, 248-254. doi: 10.1016/0003-2697(76)90527-3.
pCAMBIA 1304 vector having 35 S promoter and $-\Omega$ - translational enhancer cassette and npt for kanamycin selection.

Supplementary Figure 2 | Confirmation and characterization of transgenics. The WT and AtUPM1 overexpressor and antisense plants were grown photoperiodically (14 $\mathrm{h} \mathrm{L}$ and $10 \mathrm{~h} \mathrm{D}$ ) in MS plates for 25 days under cool-white fluorescent light at $21^{\circ} \mathrm{C}$. (A) PCR amplification of the genomic DNA with $35 \mathrm{~S}$ internal forward and AtUPM1 specific reverse primers for overexpressor (sense) plants. (B) PCR amplification of the genomic DNA with 35S internal forward and AtUPM1 forward primers for antisense plants. (C) Southern blot of PCR positive transformed T3 lines to check for the copy number of gene integration. (D) qRT PCR of the T4 homozygous plants to check the relative expression of AtUPM1 in WT and transgenic plants. (E) SDS PAGE (12.5\%) of protein $(20 \mu \mathrm{g})$ isolated from WT and transgenic plants to check equal loading and the immunoblot of the plant protein to check the abundance of AtUPM1. (F) The quantification of the AtUPM1 immunoblot using Alpha Ease FC software. IDV values represent integrated density values as calculated by the Alpha Ease FC software. Western blot data is an average of three independent replicates. qRT-PCR data are expressed as the mean \pm SEM of three independent experiments performed in triplicate.Error bars, S.D. Asterisks indicate significant difference determined by Student's t test compared to control $\left({ }^{*} P<0.05,{ }^{* *} P<0.01\right)$.

Supplementary Figure 3 | Phenotype of WT and transgenic plants grown vertically in square plates in $\mathrm{N}$ sufficient and deficient media. Arabidopsis thaliana seeds were directly germinated and grown for 3 weeks in square plates as described in Material and Methods. After 3 weeks of growth in $\mathrm{N}$ deficient (10\% N) medium the antisense plants perished.

Brindley, A. A., Raux, E., Leech, H. K., Schubert, H. L., and Warren, M. J. (2003). A Story of Chelatase Evolution: identification and characterisation of a small 13-15-kDa "ancestral" cobaltochelatase (CbiXS) in the archaea. J. Biol. Chem. 278, 22388-22395. doi: 10.1074/jbc.M3024 68200

Campbell, W. H. (1999). NITRATE REDUCTASE STRUCTURE, FUNCTION AND REGULATION: bridging the gap between biochemistry and physiology. Annu. Rev. Plant Physiol. Plant Mol. Biol. 50, 277-303. doi: 10.1146/annurev.arplant.50.1.277

Clough, S. J., and Bent, A. F. (1998). Floral dip: a simplified method for Agrobacterium-mediated transformation of Arabidopsis thaliana. Plant J. 16, 735-743. doi: 10.1046/j.1365-313x.1998.00343.x

Crane, B. R., and Getzoff, E. D. (1996). The relationship between structure and function for the sulfite reductases. Curr. Opin. Struct. Biol. 6, 744-756. doi: 10.1016/S0959-440X(96)80003-0

Crété, P., Caboche, M., and Meyer, C. (1997). Nitrite reductase expression is regulated at the post-transcriptional level by the nitrogen source in Nicotiana plumbaginifolia and Arabidopsis thaliana. Plant J. 11, 625-634. doi: 10.1046/j.1365-313X.1997.11040625.x

Demmig, B., Winter, K., Krüger, A., and Czygan, F.-C. (1987). Photoinhibition and zeaxanthin formation in intact leaves: a possible role of the Xanthophyll cycle in the dissipation of excess light energy. Plant Physiol. 84, 218-224. doi: $10.1104 /$ pp.84.2.218

Demmig-Adams, B., and Adams, W. W. (2006). Photoprotection in an ecological context: the remarkable complexity of thermal energy dissipation. New Phytol. 172, 11-21. doi: 10.1111/j.1469-8137.2006.0 1835.x

Demmig-Adams, B., Garab, G., Adams Iii, W., and University of Illinois, G. (2014). Non-photochemical Quenching and Energy Dissipation in Plants, Algae and Cyanobacteria. Dordecht: Springer.

Djennane, S., Chauvin, J. E., and Meyer, C. (2002). Glasshouse behaviour of eight transgenic potato clones with a modified nitrate reductase expression under two fertilization regimes. J. Exp. Bot. 53, 1037-1045. doi: 10.1093/jexbot/53.371.1037

Doncheva, S., Vassileva, V., and Ignatov, G. (2001). Influence of nitrogen deficiency on photosynthesis and chloroplast ultrastructure of pepper plants (Research Note). Agric. Food Sci. 10, 59-64.

Dutta, S., Mohanty, S., and Tripathy, B. C. (2009). Role of temperature stress on chloroplast biogenesis and protein import in pea. Plant Physiol. 150, 1050-1061. doi: 10.1104/pp.109.137265 
Faure, J.-D., Vincentz, M., Kronenberger, J., and Caboche, M. (1991). Coregulated expression of nitrate and nitrite reductases. Plant J. 1, 107-113. doi: 10.1111/j.1365-313X.1991.00107.x

Ferrario-Méry, S., Valadier, M.-H., Godefroy, N., Miallier, D., Hirel, B., Foyer, C. H., et al. (2002). Diurnal changes in ammonia assimilation in transformed tobacco plants expressing ferredoxin-dependent glutamate synthase mRNA in the antisense orientation. Plant Sci. 163, 59-67. doi: 10.1016/S0168-9452(02)00058-4

Foyer, C. H., and Ferrario, S. (1994). Modulation of carbon and nitrogen metabolism in transgenic plants with a view to improved biomass production. Biochem. Soc. Trans. 22, 909-915. doi: 10.1042/bst0220909

Fraisier, V., Gojon, A., Tillard, P., and Daniel-Vedele, F. (2000). Constitutive expression of a putative high-affinity nitrate transporter in Nicotiana plumbaginifolia: evidence for post-transcriptional regulation by a reduced nitrogen source. Plant J. 23, 489-496. doi: 10.1046/j.1365-313x.2000.00813.x

Gaitonde, M. K. (1967). A spectrophotometric method for the direct determination of cysteine in the presence of other naturally occurring amino acids. Biochem. J. 104, 627-633.

Garai, S., Joshi, N. C., and Tripathy, B. C. (2016). Phylogenetic analysis and photoregulation of siroheme biosynthesis genes: uroporphyrinogen III methyltransferase and sirohydrochlorin ferrochelatase of Arabidopsis thaliana. Physiol. Mol. Biol. Plants 22, 351-359. doi: 10.1007/s12298-016-0363-1

Gaude, N., Bréhélin, C., Tischendorf, G., Kessler, F., and Dörmann, P. (2007), Nitrogen deficiency in Arabidopsis affects galactolipid composition and gene expression and results in accumulation of fatty acid phytyl esters. Plant J. 49, 729-739. doi: 10.1111/j.1365-313X.2006.02992.x

Genty, B., Briantais, J.-M., and Baker, N. R. (1989). The relationship between the quantum yield of photosynthetic electron transport and quenching of chlorophyll fluorescence. Biochim. Biophys. Acta Gen. Subjects 990, 87-92. doi: 10.1016/S0304-4165(89)80016-9

Govindjee, Amesz, J., and Fork, D.C. (1986). Light Emission by Plants and Bacteria. Orlando, FL: Academic Press.

Hoagland, D. R., and Arnon, D. I. (1950). The water-culture method for growing plants without soil. Calif. Agr. Exp. Stat. 347, 1-32.

Horn, M. J., Jones, D. B., and Blum, A. E. (1946). Colorimetric determination of methionine in proteins and foods. J. Biol. Chem. 166, 313-320.

Huber, J. L., Redinbaugh, M. G., Huber, S. C., and Campbell, W. H. (1994). Regulation of maize leaf nitrate reductase activity involves both gene expression and protein phosphorylation. Plant Physiol. 106, 1667-1674. doi: $10.1104 /$ pp.106.4.1667

Huber, S. C., Sugiyama, T., and Alberte, R. S. (1989). Photosynthetic determinants of growth in maize plants: effects of nitrogen nutrition on growth, carbon fixation and photochemical features. Plant Cell Physiol. 30, 1063-1072. doi: 10.1093/oxfordjournals.pcp.a077846

Hukmani, P., and Tripathy, B. C. (1994). Chlorophyll Biosynthetic Reactions during Senescence of Excised Barley (Hordeum vulgare L. cv IB 65) Leaves. Plant Physiol. 105, 1295-1300. doi: 10.1104/pp.105.4.1295

Jarvis, P., Dörmann, P., Peto, C. A., Lutes, J., Benning, C., and Chory, J. (2000). Galactolipid deficiency and abnormal chloroplast development in the Arabidopsis MGD synthase 1 mutant. Proc. Natl. Acad. Sci. U.S.A. 97, 8175-8179. doi: 10.1073/pnas.100132197

Jiang, C.-D., Wang, X., Gao, H.-Y., Shi, L., and Chow, W. S. (2011). Systemic regulation of leaf anatomical structure, photosynthetic performance, and highlight tolerance in sorghum. Plant Physiol. 155, 1416-1424. doi: 10.1104/pp.111. 172213

Jilani, A., Kar, S., Bose, S., and Tripathy, B. C. (1996). Regulation of the carotenoid content and chloroplast development by levulinic acid. Physiol. Plant 96, 139-145. doi: 10.1111/j.1399-3054.1996.tb00194.x

Kaiser, J. J., and Lewis, O. A. M. (1984). Nitrate reductase and glutamine synthetase activity in leaves and roots of nitrate-fed Helianthus annuus L. Plant Soil 77, 127-130. doi: 10.1007/BF02182818

Kaiser, W. M., and Huber, S. C. (1994). Posttranslational regulation of nitrate reductase in higher plants. Plant Physiol. 106:817. doi: 10.1104/pp.106.3.817

Kalaji, H. M., Carpentier, R., Allakhverdiev, S. I., and Bosa, K. (2012). Fluorescence parameters as early indicators of light stress in barley. J. Photochem. Photobiol. B Biol. 112, 1-6. doi: 10.1016/j.jphotobiol.2012.03.009

Kandoi, D., Mohanty, S., Govindjee, and Tripathy, B. C. (2016). Towards efficient photosynthesis: overexpression of Zea mays phosphoenolpyruvate carboxylase in Arabidopsis thaliana. Photosyn. Res. 130, 47-72. doi: 10.1007/s11120-016-0224-3

Karnovsky, M. J. (1965). A formaldehyde-glutaraldehyde fixative of high osmolality for use in electron microscopy. J. Cell Biol. 27, 1A-138A.

Kopriva, S., Suter, M., von Ballmoos, P., Hesse, H., Krähenbühl, U., Rennenberg, H., et al. (2002). Interaction of sulfate assimilation with carbon and nitrogen metabolism in lemna minor. Plant Physiol. 130, 1406-1413. doi: $10.1104 /$ pp. 007773

Koprivova, A., Suter, M., den Camp, R. O., Brunold, C., and Kopriva, S. (2000). Regulation of sulfate assimilation by nitrogen in Arabidopsis. Plant Physiol. 122, 737-746. doi: 10.1104/pp.122.3.737

Kozaki, A., and Takeba, G. (1996). Photorespiration protects C3 plants from photooxidation. Nature 384, 557-560. doi: 10.1038/384557a0

Laemmli, U. K. (1970). Cleavage of structural proteins during the assembly of the head of bacteriophage T4. Nature 227, 680-685.

Lefebvre, S., Lawson, T., Fryer, M., Zakhleniuk, O. V., Lloyd, J. C., and Raines, C. A. (2005). Increased Sedoheptulose-1,7-Bisphosphatase activity in transgenic tobacco plants stimulates photosynthesis and growth from an early stage in development. Plant Physiol. 138, 451-460. doi: 10.1104/pp.104.055046

Leustek, T. (2002). Sulfate metabolism. Arabidopsis Book 1:e0017. doi: 10.1199/tab.0017

Leustek, T., and Saito, K. (1999). Sulfate transport and assimilation in plants. Plant Physiol. 120, 637-643. doi: 10.1104/pp.120.3.637

Leustek, T., Smith, M., Murillo, M., Singh, D. P., Smith, A. G., Woodcock, S. C., et al. (1997). Siroheme biosynthesis in higher plants. Analysis of an S-adenosyl-L-methionine-dependent uroporphyrinogen III methyltransferase from Arabidopsis thaliana. J. Biol. Chem. 272, 2744-2752. doi: 10.1074/jbc.27 2.5.2744

Livak, K. J., and Schmittgen, T. D. (2001). Analysis of relative gene expression data using real-time quantitative PCR and the 2(-Delta Delta C(T)) Method. Methods 25, 402-408. doi: 10.1006/meth.2001.1262

McAllister, C. H., Beatty, P. H., and Good, A. G. (2012). Engineering nitrogen use efficient crop plants: the current status. Plant Biotechnol. J. 10, 1011-1025. doi: 10.1111/j.1467-7652.2012.00700.x

Miyagawa, Y., Tamoi, M., and Shigeoka, S. (2001). Overexpression of a cyanobacterial fructose-1,6-/sedoheptulose-1,7-bisphosphatase in tobacco enhances photosynthesis and growth. Nat. Biotechnol. 19, 965-969. doi: $10.1038 /$ nbt1001-965

Mochizuki, N., Brusslan, J. A., Larkin, R., Nagatani, A., and Chory, J. (2001). Arabidopsis genomes uncoupled 5 (GUN5) mutant reveals the involvement of Mg-chelatase H subunit in plastid-to-nucleus signal transduction. Proc. Natl. Acad. Sci. U.S.A. 98, 2053-2058. doi: 10.1073/pnas.98.4.2053

Murashige, T., and Skoog, F. (1962). A revised medium for rapid growth and bio assays with tobacco tissue cultures. Physiol. Plant. 15, 473-497. doi: 10.1111/j.1399-3054.1962.tb08052.x

Murphy, M. J., and Siegel, L. M. (1973). Siroheme and sirohydrochlorin. The basis for a new type of porphyrin-related prosthetic group common to both assimilatory and dissimilatory sulfite reductases. J. Biol. Chem. 248, 6911-6919.

Murphy, M. J., Siegel, L. M., Tove, S. R., and Kamin, H. (1974). Siroheme: a new prosthetic group participating in six-electron reduction reactions catalyzed by both sulfite and nitrite reductases. Proc. Natl. Acad. Sci. U.S.A. 71, 612-616.

Nakayama, M., Akashi, T., and Hase, T. (2000). Plant sulfite reductase: molecular structure, catalytic function and interaction with ferredoxin. J. Inorganic Biochem. 82, 27-32. doi: 10.1016/S0162-0134(00)00138-0

Oelmüller, R., Levitan, I., Bergfeld, R., Rajasekhar, V. K., and Mohr, H. (1986). Expression of nuclear genes as affected by treatments acting on the plastids. Planta 168, 482-492. doi: 10.1007/BF00392267

Oliveira, I. C., Brears, T., Knight, T. J., Clark, A., and Coruzzi, G. M. (2002). Overexpression of cytosolic glutamine synthetase. Relation to nitrogen, light, and photorespiration. Plant Physiol. 129, 1170-1180. doi: 10.1104/pp. 020013

Papageorgiou, G., and Govindjee (2004). Chlorophyll a fluorescence: a probe of photosynthesis. Dordecht: Springer.

Pattanayak, G. K., Biswal, A. K., Reddy, V. S., and Tripathy, B. C. (2005). Light-dependent regulation of chlorophyll b biosynthesis in chlorophyllide a oxygenase overexpressing tobacco plants. Biochem. Biophys. Res. Commun. 326, 466-471. doi: 10.1016/j.bbrc.2004.11.049. 
Pattanayak, G. K., and Tripathy, B. C. (2002). Catalytic function of a novel protein protochlorophyllide oxidoreductase C of Arabidopsis thaliana. Biochem. Biophys. Res. Commun. 291, 921-924. doi: 10.1006/bbrc.2002. 6543

Pattanayak, G. K., and Tripathy, B. C. (2011). Overexpression of protochlorophyllide oxidoreductase $\mathrm{C}$ regulates oxidative stress in Arabidopsis. PLoS ONE 6:e26532. doi: 10.1371/journal.pone.00 26532

Pattanayak, G. K., and Tripathy, B. C. (2016). Modulation of biosynthesis of photosynthetic pigments and light-harvesting complex in wild-type and gun5 mutant of Arabidopsis thaliana during impaired chloroplast development. Protoplasma 253, 747-752. doi: 10.1007/s00709-016-0958-y

Porra, R. J., Thompson, W. A., and Kriedemann, P. E. (1989). Determination of accurate extinction coefficients and simultaneous equations for assaying chlorophylls $\mathrm{a}$ and $\mathrm{b}$ extracted with four different solvents: verification of the concentration of chlorophyll standards by atomic absorption spectroscopy. Biochim. Biophys. Acta Bioenerget. 975, 384-394. doi: 10.1016/S0005-2728(89)80347-0

Quilleré, I., Dufossé, C., Roux, Y., Foyer, C. H. F., Caboche, M., and Morot-Gaudry, J.-F. (1994). The effects of deregulation of NR gene expression on growth and nitrogen metabolism of Nicotiana plumbaginifolia plants. J. Exp. Bot. 45, 1205-1211. doi: 10.1093/jxb/45.9.1205

Raux-Deery, E., Leech, H. K., Nakrieko, K. A., McLean, K. J., Munro, A. W., Heathcote, P., et al. (2005). Identification and characterization of the terminal enzyme of siroheme biosynthesis from Arabidopsis thaliana: a plastid-located sirohydrochlorin ferrochelatase containing a $2 \mathrm{Fe}-2 \mathrm{~S}$ center. J. Biol. Chem. 280, 4713-4721. doi: 10.1074/jbc.M411360200

Robertson, G. P., and Vitousek, P. M. (2009). Nitrogen in agriculture: balancing the cost of an essential resource. Annu. Rev. Environ. Resour. 34, 97-125. doi: 10.1146/annurev.environ.032108.105046

Rufty, T. W., Huber, S. C., and Volk, R. J. (1988). Alterations in leaf carbohydrate metabolism in response to nitrogen stress. Plant Physiol. 88, 725-730. doi: $10.1104 / p p \cdot 88.3 .725$

Saha, K., Webb, Michael E. W., Stephen, E. J. R., Helen, K. L., Martin, J. W., and Alison, G. S. (2012). Characterization of the evolutionarily conserved iron "sulfur cluster of sirohydrochlorin ferrochelatase from Arabidopsis thaliana. Biochem. J. 444, 227-237. doi: 10.1042/bj20111993

Sakuraba, Y., Schelbert, S., Park, S.-Y., Han, S.-H., Lee, B.-D., Andrès, C. B., et al. (2012). STAY-GREEN and chlorophyll catabolic enzymes interact at lightharvesting Complex II for Chlorophyll Detoxification during Leaf Senescence in Arabidopsis. Plant Cell 24, 507-518. doi: 10.1105/tpc.111.089474

Sambrook, J., and Russell, D. W. (2001). Molecular Cloning: A Laboratory Manual, 3rd Edn. Vol 1, 2 and 3. Cold Spring Harbor, NY: Cold Spring Harbor Laboratory Press.

Schlicke, H., Hartwig, A. S., Firtzlaff, V., Richter, A. S., Glässer, C., Maier, K., et al. (2014). Induced deactivation of genes encoding chlorophyll biosynthesis enzymes disentangles tetrapyrrole-mediated retrograde signaling. Mol. Plant 7, 1211-1227. doi: 10.1093/mp/ssu034

Schreiber, U. (2004). Pulse-Amplitude-Modulation (PAM) Fluorometry and Saturation Pulse Method: an Overview. Dordrecht: Springer.

Schreiber, U., and Armond, P. A. (1978). Heat-induced changes of chlorophyll fluorescence in isolated chloroplasts and related heat-damage at the pigment level. Biochim. Biophys. Acta 502, 138-151. doi: 10.1016/0005-2728(78)90138-X

Schreiber, U., Bilger, W., and Neubauer, C. (1995). Chlorophyll Fluorescence as a Nonintrusive Indicator for Rapid Assessment of in Vivo Photosynthesis. Berlin: Springer.

Seligman, K., Saviani, E. E., Oliveira, H. C., Pinto-Maglio, C. A., and Salgado, I. (2008). Floral transition and nitric oxide emission during flower development in Arabidopsis thaliana is affected in nitrate reductase-deficient plants. Plant Cell Physiol. 49, 1112-1121. doi: 10.1093/pcp/pcn089
Shalygo, N., Czarnecki, O., Peter, E., and Grimm, B. (2009). Expression of chlorophyll synthase is also involved in feedback-control of chlorophyll biosynthesis. Plant Mol. Biol. 71, 425-436. doi: 10.1007/s11103-009-9532-8

Shi, J., Yi, K., Liu, Y., Xie, L., Zhou, Z., Chen, Y., et al. (2015). Phosphoenolpyruvate carboxylase in arabidopsis leaves plays a crucial role in carbon and nitrogen metabolism. Plant Physiol. 167, 671-681. doi: 10.1104/pp.114.254474

Sood, S., Gupta, V., and Tripathy, B. C. (2005). Photoregulation of the greening process of wheat seedlings grown in red light*. Plant Mol. Biol. 59, 269-287. doi: 10.1007/s11103-005-8880-2

Strasser, R. J., Srivastava, A., and Govindjee (1995). POLYPHASIC CHLOROPHYLL a FLUORESCENCE TRANSIENT IN PLANTS AND CYANOBACTERIA*. Photochem. Photobiol. 61, 32-42. doi: 10.1111/j.1751-1097.1995.tb09240.x

Sutton, M. A., Oenema, O., Erisman, J. W., Leip, A., van Grinsven, H., and Winiwarter, W. (2011). Too much of a good thing. Nature 472, 159-161. doi: 10.1038/472159a.

Takahashi, M., Sasaki, Y., Ida, S., and Morikawa, H. (2001). Nitrite reductase gene enrichment improves assimilation of $\mathrm{NO}(2)$ in Arabidopsis. Plant Physiol. 126, 731-741. doi: $10.1104 /$ pp.126.2.731

Tanaka, R., and Tanaka, A. (2007). Tetrapyrrole biosynthesis in higher plants. Аnnu. Rev. Plant Biol. 58, 321-346. doi: 10.1146/annurev.arplant.57.032905.105448

Tripathy, B. C., Sherameti, I., and Oelmüller, R. (2010). Siroheme: an essential component for life on earth. Plant Signal. Behav. 5, 14-20. doi: $10.4161 /$ psb.5.1.10173

Vincentz, M., and Caboche, M. (1991). Constitutive expression of nitrate reductase allows normal growth and development of Nicotiana plumbaginifolia plants. EMBO J. 10, 1027-1035.

Warren, M. J., Stolowich, N. J., Santander, P. J., Roessner, C. A., Sowa, B. A., and Scott, A. I. (1990). Enzymatic synthesis of dihydrosirohydrochlorin (precorrin2 ) and of a novel pyrrocorphin by uroporphyrinogen III methylase. FEBS Lett. 261, 76-80. doi: 10.1016/0014-5793(90)80640-5

Wellburn, A. R., and Lichtenthaler, H. (1984). "Formulae and program to determine total carotenoids and chlorophylls $\mathrm{A}$ and $\mathrm{B}$ of leaf extracts in different solvents," in Advances in Photosynthesis Research, ed. C. Sybesma (Dordrecht: Springer), 9-12.

Wilkinson, J. Q., and Crawford, N. M. (1991). Identification of the Arabidopsis CHL3 gene as the nitrate reductase structural gene NIA2. Plant Cell 3, 461-471. doi: $10.1105 /$ tpc.3.5.461

Yoshida, S. (1972). Physiological aspects of grain yield. Annu. Rev. Plant Physiol. 23, 437-464. doi: 10.1146/annurev.pp.23.060172.002253

Zhao, M. G., Chen, L., Zhang, L. L., and Zhang, W. H. (2009). Nitric reductase-dependent nitric oxide production is involved in cold acclimation and freezing tolerance in Arabidopsis. Plant Physiol. 151, 755-767. doi: 10.1104/pp.109.140996

Zhou, Z., He, H., Ma, L., Yu, X., Mi, Q., Pang, J., et al. (2015). Overexpression of a $G m C n x 1$ gene enhanced activity of nitrate reductase and aldehyde oxidase, and boosted mosaic virus resistance in Soybean. PLoS ONE 10:e0124273. doi: 10.1371/journal.pone. 0124273

Conflict of Interest Statement: The authors declare that the research was conducted in the absence of any commercial or financial relationships that could be construed as a potential conflict of interest.

Copyright $\odot 2018$ Garai and Tripathy. This is an open-access article distributed under the terms of the Creative Commons Attribution License (CC BY). The use, distribution or reproduction in other forums is permitted, provided the original author(s) or licensor are credited and that the original publication in this journal is cited, in accordance with accepted academic practice. No use, distribution or reproduction is permitted which does not comply with these terms. 